\title{
Performance report of the RHUM-RUM ocean bottom seismometer network around La Réunion, western Indian Ocean
}

\author{
S. C. Stähler ${ }^{1,6}$, K. Sigloch ${ }^{2,1}$, K. Hosseini ${ }^{1}$, W. C. Crawford ${ }^{3}$, G. Barruol ${ }^{4}$, M. C. Schmidt-Aursch ${ }^{5}$, \\ M. Tsekhmistrenko ${ }^{2,5}$, J.-R. Scholz ${ }^{4,5}$, A. Mazzullo ${ }^{3}$, and M. Deen ${ }^{3}$ \\ ${ }^{1}$ Dept. of Earth Sciences, Ludwig-Maximilians-Universität München, Theresienstrasse 41, 80333 Munich, Germany \\ ${ }^{2}$ Dept. of Earth Sciences, University of Oxford, South Parks Road, Oxford, OX1 3AN, UK \\ ${ }^{3}$ Institut de Physique du Globe de Paris, Sorbonne Paris Cité, UMR7154 - CNRS, Paris, France \\ ${ }^{4}$ Laboratoire GéoSciences Réunion, Université de La Réunion, Institut de Physique du Globe de Paris, Sorbonne Paris Cité, \\ UMR7154 - CNRS, Université Paris Diderot, Saint Denis CEDEX 9, France \\ ${ }^{5}$ Alfred Wegener Institute, Helmholtz Centre for Polar and Marine Research, Am Alten Hafen 26, \\ 27568 Bremerhaven, Germany \\ ${ }^{6}$ Leibniz-Institute for Baltic Sea Research, Seestraße 15, 18119 Rostock, Germany
}

Correspondence to: S. Stähler (staehler@geophysik.uni-muenchen.de)

Received: 21 July 2015 - Revised: 23 December 2015 - Accepted: 21 January 2016 - Published: 2 February 2016

\begin{abstract}
RHUM-RUM is a German-French seismological experiment based on the sea floor surrounding the island of La Réunion, western Indian Ocean (Barruol and Sigloch, 2013). Its primary objective is to clarify the presence or absence of a mantle plume beneath the Reunion volcanic hotspot. RHUM-RUM's central component is a 13-month deployment (October 2012 to November 2013) of 57 broadband ocean bottom seismometers (OBS) and hydrophones over an area of $2000 \times 2000 \mathrm{~km}^{2}$ surrounding the hotspot. The array contained 48 wideband OBS from the German DEPAS pool and 9 broadband OBS from the French INSU pool. It is the largest deployment of DEPAS and INSU OBS so far, and the first joint experiment.

This article reviews network performance and data quality: of the 57 stations, 46 and 53 yielded good seismometer and hydrophone recordings, respectively. The 19751 total deployment days yielded 18735 days of hydrophone recordings and 15941 days of seismometer recordings, which are 94 and $80 \%$ of the theoretically possible yields.

The INSU seismic sensors stand away from their OBS frames, whereas the DEPAS sensors are integrated into their frames. At long periods ( $>10 \mathrm{~s}$ ), the DEPAS seismometers are affected by significantly stronger noise than the INSU seismometers. On the horizontal components, this can be explained by tilting of the frame and buoy assemblage, e.g. through the action of ocean-bottom currents, but in ad-
\end{abstract}

dition the DEPAS intruments are affected by significant selfnoise at long periods, including on the vertical channels. By comparison, the INSU instruments are much quieter at periods $>30 \mathrm{~s}$ and hence better suited for long-period signals studies.

The trade-off of the instrument design is that the integrated DEPAS setup is easier to deploy and recover, especially when large numbers of stations are involved. Additionally, the wideband sensor has only half the power consumption of the broadband INSU seismometers. For the first time, this article publishes response information of the DEPAS instruments, which is necessary for any project where true ground displacement is of interest. The data will become publicly available at the end of 2017.

\section{Introduction}

RHUM-RUM, short for "Reunion Hotspot and Upper Mantle - Réunions Unterer Mantel”, is a German-French experiment that investigates the mantle beneath the Reunion ocean island hotspot from crust to core, using a multitude of seismological and marine geophysical methods (Barruol and Sigloch, 2013). The project also studies the hypothesized interaction between the hotspot and its surrounding mid-ocean ridges (Morgan, 1978; Dyment et al., 2007). The core of the exper- 
iment is a deployment of 48 German wideband and 9 French broadband ocean-bottom seismometers (OBS), from the DEPAS (Deutscher Geräte-Pool für Amphibische Seismologie, managed by AWI Bremerhaven) and INSU (Institut national des sciences de l'Univers) pools respectively (see Table 1 for the data return).

There have been multiple experiments in tectonic settings similar to RHUM-RUM: 35 wideband and broadband OBS from the US OBS Instrument Pool (OBSIP) were deployed by the PLUME Hawaii experiment (Laske et al., 2009; Wolfe et al., 2009) twice for 1 year. Japanese large-scale imaging efforts around an oceanic hotspot were the PLUME Tahiti experiment with 9 Japanese broadband OBS (BBOBS) (Barruol, 2002; Suetsugu et al., 2005) and the TIARES array with again 9 BBOBS around the Society hotspot (Suetsugu et al., 2012). In 2011-2012, 24 German DEPAS OBS were deployed around the Tristan da Cunha hotspot (ISOLDE experiment, Geissler and Schmidt, 2013). Other larger, longterm DEPAS deployments in non-hotspot settings were in the Aegean Sea (EGELADOS, Meier et al., 2007) and in the Gulf of Cadiz (NEAREST, Geissler et al., 2010).

RHUM-RUM has been the largest DEPAS deployment so far in terms of the number of stations deployed $(44+4)$ and in terms of aperture. This allows to resolve the deep-mantle signature of a plume using seismic tomography, especially when combined with concurrent land deployments. It is the first OBS experiment that specifically tries to use data for waveform tomography. This requires full response information on all instruments and also a high signal-to-noise ratio in the whole frequency range between 0.01 and $1 \mathrm{~Hz}$.

The central component of the experiment was a deployment of 44 wideband OBS from DEPAS, of the so-called "LOBSTER" (Longterm OBS for Tsunami and Earthquake Research) type; 4 from Geomar Kiel, essentially identical to the DEPAS LOBSTERs; and 9 LCPO2000 broadband OBS from INSU, which are based on the "L-CHEAPO" instrument (Low-Cost Hardware for Earth Applications and Physical Oceanography) developed at the Scripps Institution of Oceanography (SIO).

We report on, and compare, the performance of seismometers and hydrophones from the two involved instrument pools, the German DEPAS and the French Parc Sismomètre Fond de Mer of INSU. This is the first side-byside comparison of instruments from the German and French community OBS pools.

Data from the RHUM-RUM ocean bottom stations (and island stations) will be made freely available at the end of 2017 (Barruol et al., 2011).

This paper reviews the functioning of the OBS network and documents issues encountered in data collection, quality control, and processing. We review the experiment layout in Sect. 2.1, and the two types of OBS employed in Sect. 2.2. The performance of the stations is described in Sect. 3, with a focus on noise levels in Sect. 3.3. Possible reasons for the surprisingly different noise levels are discussed in Sect. 4.
Table 1. Data return in RHUM-RUM experiment.

\begin{tabular}{ll}
\hline Data return: & \# of stations \\
\hline $\begin{array}{l}\text { Data return on all four channels throughout } \\
\text { the entire deployment: }\end{array}$ & 27 \\
$\begin{array}{l}\text { Data return on all four channels for only } \\
\text { part of the deployment: }\end{array}$ & 18 \\
$\begin{array}{l}\text { Only hydrophone data throughout the entire } \\
\text { deployment: }\end{array}$ & 1 \\
Only hydrophone data for only part of the & 7 \\
deployment: & \\
No data returned: & 4 \\
Total number of stations deployed: & 57 \\
\hline Data days recorded: & 18735 \\
\hline Data days (hydrophones): & 15941 \\
Data days (seismometers): & 19751 \\
Deployment days: & $94 \%$ \\
Percent data recovery (hydrophones): & $80 \%$ \\
Percent data recovery (seismometers): & \\
\hline
\end{tabular}

Appendix A contains a detailed description of the seismometer instrument responses, Appendix B describes an experiment to estimate clock drift rates and Appendix $C$ contains a station-by-station list of noise levels in three period bands.

\section{Experiment setup and instrumentation}

\subsection{The OBS network}

For an overview of the whole network see Fig. 1. The oceanic component of the RHUM-RUM experiment consisted of 57 broadband ocean bottom seismometers deployed over an area of $2000 \mathrm{~km} \times 2000 \mathrm{~km}$ from September 2012 to November 2013. The OBS clustered relatively densely around the island of La Réunion, out to distances of $400-500 \mathrm{~km}$, including the vicinity of Mauritius (Fig. 1). This relative dense coverage was extended eastward to the Central Indian Ridge, in order to investigate hypothesized asthenospheric flow from hotspot to ridge (Morgan, 1978; Dyment et al., 2007). The seismicity in the reliably active South Sandwich subduction zone generates body-wave paths which sample the mantle beneath La Réunion at greater depths. Sampling with opposite azimuth is provided by earthquakes in the subduction zones of the south west Pacific, especially since the OBS network is augmented by RHUM-RUM land stations on Madagascar, and on the Îles Éparses in the Mozambique Channel. A linear, less dense arrangement of OBS followed the strike of the Central Indian and Southwest Indian ridges to the east and south, at $800-1200 \mathrm{~km}$ distance from the hotspot. Waves originating from earthquakes in the Alpine-Himalayan orogens and recorded at these stations again sample deeper levels of the mantle beneath La Réunion, but are also used to study the mid-ocean ridges themselves. A dense sub-array 


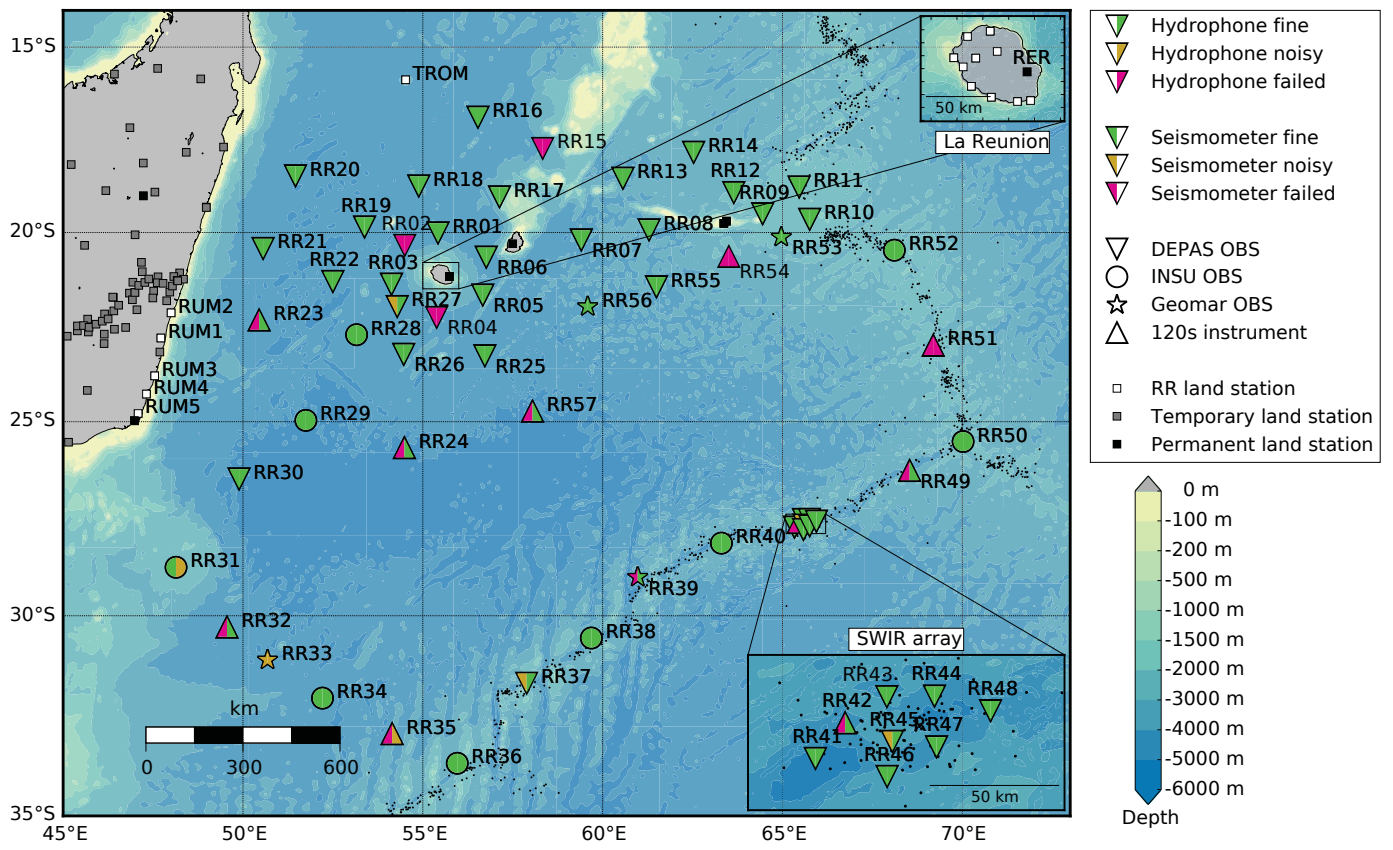

Figure 1. Overview map of the RHUM-RUM ocean bottom seismometer network. OBS are marked by large coloured symbols. Symbol shape marks the station type: DEPAS LOBSTER (inverted triangle), INSU LCPO2000 (circle), Geomar OBS (star). DEPAS instruments with malfunctioning $120 \mathrm{~s}$ instruments are marked as regular triangles. Two halves of the inner symbol indicate the functioning of the seismic sensors and hydrophones, respectively. Green indicates good performance; orange, high noise levels; red means the instrument failed to record. White squares indicate temporary land stations as part of the RHUM-RUM network YV, grey square indicate temporary land stations as part of the MACOMO (Wysession et al., 2012) and SELASOMA (Tilmann et al., 2012) projects, which were both installed between 2012 and 2014. Black squares indicate permanent GEOSCOPE stations. Small black dots mark earthquake hypocentres above magnitude 4 between 1981 and 2015, as published by the Preliminary Determination of Epicentres (PDE) bulletin of the US National Earthquake Information Center (NEIC). The seismicity is mainly concentrated on the oceanic ridges. Colour-shaded bathymetry is based on the global 30 arcsec merged bathymetry dataset by Becker et al. (2009), available at: http://topex.ucsd.edu/WWW_html/srtm30_plus.html.

of 8 OBS, referred to as the "SWIR Array", was deployed around an active seamount on the Southwest Indian Ridge in order to investigate the structure and seismicity of this ultraslow spreading ridge. The sub-array had a footprint of about $70 \mathrm{~km} \times 50 \mathrm{~km}$ and was located in segment 8 of the ridge, following the nomenclature of Cannat et al. (1999).

The OBS were deployed in October 2012 by the French research vessel Marion Dufresne and were recovered in October/November 2013 by the German research vessel Meteor. The instruments spent the intervening 13 months recording on the seafloor.

At each deployment site, the seafloor was surveyed with R/V Marion Dufresne's multi-beam bathymeter and sediment echo sounder before dropping the OBS over board in a location deemed most suitable. The ship left immediately after deployment so that only deployment (and recovery) coordinates are known; no attempt was made to acoustically triangulate the landing positions of the OBS, with the notable exception of the 8 OBS in the densified SWIR Array. In general, OBS recovery positions were found to differ from their deployment positions by no more than a few hundred meters.

\subsection{OBS models deployed}

Here we give a brief overview of the hardware deployed (see Table 2) and the recording settings used, especially as they relate to the performance assessment of Sect. 3 (see Table 2 for an overview).

\subsubsection{LOBSTER}

The broadband OBS pool DEPAS (Deutscher Geräte-Pool für Amphibische Seismologie) of the German geophysical community consists of 80 instruments of the LOBSTER type ("Long-term OBS for Tsunami and Earthquake Research"). The OBS were developed in 2005, merging previous design experience mainly by Geomar Kiel (Flueh and Biolas, 1996), the University of Hamburg (Dahm et al., 2002), and the marine engineering firm K.U.M. (Umwelt- und Meerestechnik Kiel). K.U.M. was charged with building 80 LOBSTER units, which were funded by the German Research Foundation (DFG), the Federal Ministry of Education and Research (BMBF) and the Helmholtz Association of National Research Centres (HGF). The Alfred Wegener Institute Bremerhaven houses and maintains the instruments. For 

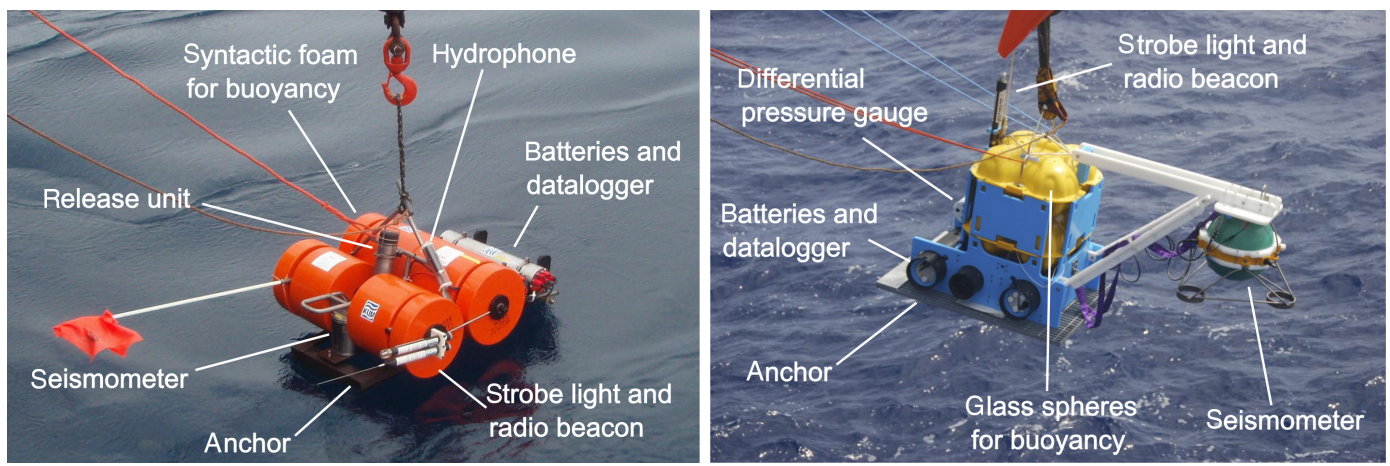

Figure 2. Broadband ocean-bottom seismometers, photographed seconds before deployment. Left panel: one of 48 LOBSTER-type instruments from the German DEPAS pool. The Güralp CMG-OBS40T sensor (corner period $60 \mathrm{~s}$ ) is fitted in a vertical titanium pressure cylinder between two syntactic foam buoys and wedged against the steel anchor beneath it. Two horizontal titanium cylinders in the background contain the data recorder and the lithium batteries. The broadband hydrophone (corner period $100 \mathrm{~s}$ ) is strapped to the A-shaped titanium frame that protrudes from the centre of the buoy assemblage. Right panel: one of 9 LCPO2000-BBOBS (Scripps-based) instruments from the French Parc de Sismomètre Fond de Mer pool at INSU. The Nanometrics Trillium sensor (corner period $240 \mathrm{~s}$ ) is contained in the green sphere, which is dropped (i.e. mechanically separated) from the main frame one hour after arrival on the seabed. The differential pressure gauge is located in the white cylinder behind the frame. Both instruments are equipped with flags, strobe lights and radio beacons to facilitate recovery.

detailed information see http://www.awi.de/depas. The four OBS loaned to RHUM-RUM by Geomar Kiel are essentially identical to the DEPAS OBS.

The modular LOBSTER design (Fig. 2, left panel) is based on an open titanium frame that holds three titanium cylinders (containing the seismic sensor, data acquisition unit, and lithium batteries) and syntactic foam buoys that provide buoyancy for the ascent during recovery. A fourth titanium cylinder contains a mechanical release unit that locks the frame assemblage to a steel anchor until an acoustic release signal is received that initiates detachment from the anchor. The hydrophone is strapped to the frame, as are various recovery aides (a radio beacon, a flash, a flag, and a head buoy).

The titanium tube holding the seismic sensor is seated vertically between two syntactic foam units, and is wedged against the steel anchor by a steel plate, which acts as a lever that is pre-loaded by the mechanical release unit, thus ensuring good seismic coupling to the anchor. The integration of the seismometer into the frame makes the design very sturdy and reduces the number of failure points, but it also means that the seismometer is likely to record any tilt noise created by currents or pressure fluctuations acting on the frame. The orientation of the seismometer channels is fixed with respect to the frame, as it is shown in Fig. 3.

The seismic sensor in most DEPAS units is a threecomponent wideband Güralp CMG-OBS40T with a corner period of $60 \mathrm{~s}$. The CMG-OBS40T is a lesser-known version of the CMG-40T with reduced power consumption, which is mounted in a gimbal system for usage in OBS. The gimbal system is activated three days after arrival on the seafloor to ensure proper levelling, since the instrument may land in a

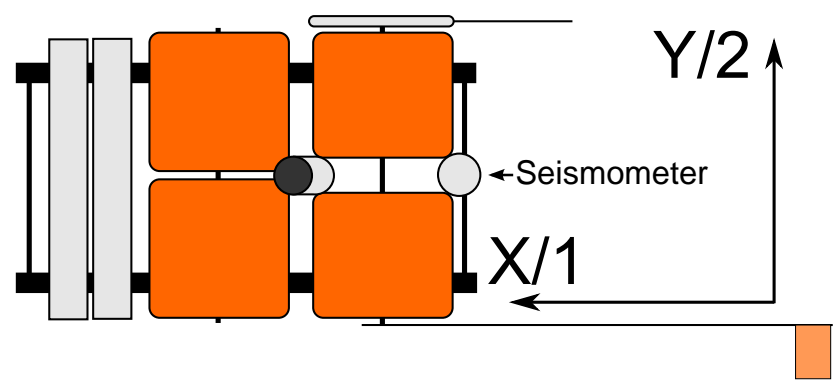

Figure 3. Sketch of a LOBSTER frame with the orientation of the horizontal seismometer channels. The $X$ channel is oriented along the long axis of the LOBSTER, the $Y$ channel $90^{\circ}$ clock-wise of it. Positive values in the seismogram correspond to movement in the direction of the arrow. For the vertical $(Z)$ channel, positive values correspond to upward movement. In the RESIF data archive, the $X$ channel is stored as $\mathrm{BH} 1$, the $Y$ channel as $\mathrm{BH} 2$ and the $Z$ channel as BHZ.

tilted position) and then once every 21 days since the seafloor may settle over time.

The seismometer is sold in versions with different upper corner periods $(10,30,60 \mathrm{~s})$. All are mechanically identical, but use different feedback mechanisms to control the flat part of the response curve. The $60 \mathrm{~s}$ version is used by DEPAS and other OBS pools in Europe (e.g. IDL, Lisbon). Nine out of 48 instruments used in RHUM-RUM featured a prototype, broadband sensor design (corner period of $120 \mathrm{~s}$ ). All of these nine units failed to level under deep-sea conditions, and repeated, unsuccessful levelling attempts drained the batteries prematurely (see Sect. 3.1).

The DEPAS units were additionally equipped with broadband hydrophones of type HTI-01 and HTI-04-PCA/ULF 
Table 2. Comparison of German (DEPAS) and French (INSUIPGP) OBS types.

\begin{tabular}{lll}
\hline Pool & DEPAS & INSU-IPGP \\
\hline Manufacturer & K.U.M., Kiel & $\begin{array}{l}\text { Scripps/INSU- } \\
\text { IPGP }\end{array}$ \\
OBS type & LOBSTER & $\begin{array}{l}\text { LCPO2000- } \\
\text { BBOBS }\end{array}$ \\
& & $25 / 350 \mathrm{~kg}$ \\
Weight (water/air) & $30 / 400 \mathrm{~kg}$ & $2 \mathrm{~h}(2$ persons) \\
Assembly time & $30 \mathrm{~min}(2$ persons) & 8 in a $20^{\prime}$ container \\
Transport options & 12 in a $20^{\prime}$ container & Glass spheres \\
Buoyancy & Syntactic foam & Aluminium \\
Instrument casing & Titanium & $\begin{array}{l}\text { Trillium } 2400 B S \\
\text { (240 s) }\end{array}$ \\
Seismometer & CMG-OBS40T & in external probe \\
Placement & integrated into frame & $700 \mathrm{~mW}$ (seism.) \\
Power consumption & $100 \mathrm{~mW}$ (seism.) & $600 \mathrm{~mW}$ (recorder) \\
\hline
\end{tabular}

manufactured by HighTechInc (corner period 100 s), which usually worked very reliably as long as power was available.

The deepest RHUM-RUM OBS was deployed at $5400 \mathrm{~m}$ depth (Table 3), and the standard DEPAS OBS is certified to $6000 \mathrm{~m}$ water depth. Two battery tubes can be fitted with up to 180 lithium cells, sufficient for up to 15 months of recording using the settings described below. RHUM-RUM instruments were equipped to record for 13 months at sampling rates of $50 \mathrm{~Hz}$. Eight of the 48 available DEPAS units were of a deep-diving variant certified to $7300 \mathrm{~m}$ depth, which has only one battery tube and therefore holds fewer batteries. Most of these instruments were deployed in the SWIR sub-array and typically recorded for 8-9 months at a sampling rate of $100 \mathrm{~Hz}$ (higher rate in order to investigate local seismicity). The clocks are supposed to continue running even after the voltage has dropped below the level required for data recording, in order to enable estimates of clock drift even if OBS retrieval is delayed.

\subsubsection{The Scripps OBS instrument, INSU instrument pool}

The INSU instruments (Fig. 2, right panel) are of the LCPO2000-BBOBS type, which is based on the Scripps Institution of Oceanography (SIO) "L-CHEAPO" design. Three of the instruments were manufactured at SIO and the other six at the INSU-IPGP OBS facility. The data recorder, batteries and release unit are protected in aluminium cylinders. The seismic sensor sits in an aluminium sphere. Buoyancy for recovery is created by hollow glass spheres.

All instruments were equipped with Nanometrics Trillium-240 seismometers with a corner period of $240 \mathrm{~s}$ and a differential pressure gauge with a passband between 0.002 to $30 \mathrm{~Hz}$.

The INSU instruments check their level every hour. This caused an electronic spike of approximately 600 counts on the seismometer channels (see Sect. 3). This same spike exists in the 2006-2007 PLUME data set using SIO BBOBS (Laske et al., 2009), although we found no published mention of it. The problem has not been explicitly solved, but the SIO BBOBSs were reprogrammed after the PLUME experiment to only check level once a week after the initial levelling cycle and the INSU BBOBSs are currently being reprogrammed to do the same. Work has been done to remove the hourly spike in the PLUME data (G. Laske, personal communication, 2014) and is being repeated for the RHUM-RUM data: it would be good to publish the correction algorithms, because these instruments probably still have this spike once per week.

The INSU instruments use a differential pressure gauge (DPGs, Cox et al., 1984) rather than a hydrophone. The DPG sits on the lower instrument frame close to the battery cylinder (Fig. 2).

\subsection{Instrument responses}

Instrument responses specify the transfer functions of seismometers and hydrophones (three seismogram channels and one hydrophone channel per station). The RESIF (RÉseau SIsmologique $\&$ géodésique Français) data centre serves this information in the format of StationXML or dataless SEED files.

To our knowledge, detailed meta-data information for DEPAS OBS has not been published elsewhere. Therefore, we added a detailed discussion of the instrument responses as an appendix to this paper (Sect. A). Figures 4 and 5 show the total responses of instruments and data loggers for hydrophones and seismometers. Figure 6 shows instrumentcorrected waveforms. For all seismometer types, instrument correction results in the same $\mathrm{P}$-waveform.

\section{Network performance}

All 57 OBS were recovered successfully and undamaged. Table 3 summarizes the state of health of all seismometers and hydrophones over the deployment period. For a graphical summary of network performance (see Fig. 7).

Deployments were staggered over four weeks, along the $15000 \mathrm{~km}$-long cruise track. Recovery took five weeks and proceeded in roughly the same order as deployment, so that all stations spent approximately 13 months on the sea floor. An early end of recording was anticipated for stations RR35, RR41, RR43-RR48, and RR51 because their single battery tube only accommodated batteries for $8-9$ months. For other stations, premature end of recording reflects technical issues, as discussed below.

Following the definition of the Cascadia initiative (Sumy et al., 2015), the data recovery was 15941 data days out of 19751 deployment days or $80 \%$ for the seismometers, and 18735 data days or $94 \%$ for the hydrophones (Table 1). 
Table 3. Performance summary of the 57 RHUM-RUM OBS and hydrophones. The abbrevation "gz" in the status column refers to the "glitch" on the $Z$ component of the INSU seismograms (see Sect. 3.1). Skew is the measured clock drift in s, i.e. the instrument time at recovery minus the GPS time at recovery ("NA" if unknown because clock stopped early). For DEPAS stations, the number of recording days can exceed the number of deployment days because recording was started on deck prior to deployment. In the comments column, "120 s inst." refers to the new DEPAS sensor type that failed to level, yielding no useful seismometer data; "Geomar" refers to an OBS from Geomar, similar to the DEPAS LOBSTER. Figure 7 summarizes the network's state of health over the deployment period of October 2012 to November 2013.

\begin{tabular}{|c|c|c|c|c|c|c|c|c|c|c|c|c|c|}
\hline $\begin{array}{l}\text { Station } \\
\text { name }\end{array}$ & Latitude & Longitude & $\begin{array}{l}\text { Depth } \\
{[\mathrm{m}]}\end{array}$ & $\begin{array}{l}\text { Deployment } \\
\text { date } \\
\text { [UTC] }\end{array}$ & $\begin{array}{l}\text { Recovery } \\
\text { date } \\
{[\mathrm{UTC}]}\end{array}$ & $\begin{array}{l}\text { End of } \\
\text { record } \\
{[\mathrm{UTC}]}\end{array}$ & $\begin{array}{l}\text { Install. time } \\
\text { [days] }\end{array}$ & $\begin{array}{l}\text { Record } \\
\text { length } \\
\text { [days] }\end{array}$ & s.r. [Hz] & $\begin{array}{l}\text { Seismo } \\
\text { status }\end{array}$ & $\begin{array}{l}\text { Hydro } \\
\text { status }\end{array}$ & $\begin{array}{l}\text { Skew } \\
\text { value }\end{array}$ & Notes \\
\hline RR01 & -20.0069 & 55.4230 & 4298 & 5 Oct 2012 & 6 Nov 2013 & 6 Nov 2013 & 397 & 397 & 50 & good & good & $0.67 \mathrm{~s}$ & \\
\hline RR02 & -20.3392 & 54.4984 & 4436 & 5 Oct 2012 & 6 Nov 2013 & 5 Oct 2012 & 396 & 0 & 50 & failed & failed & NA & \\
\hline RR03 & -21.3732 & 54.1294 & 4340 & 5 Oct 2012 & 5 Nov 2013 & 5 Nov 2013 & 396 & 396 & 50 & good & good & $0.81 \mathrm{~s}$ & \\
\hline RR04 & -22.2553 & 55.3846 & 4168 & 5 Oct 2012 & 5 Nov 2013 & 7 Oct 2012 & 396 & 2 & 50 & failed & failed & NA & \\
\hline RR05 & -21.6626 & 56.6676 & 4092 & 3 Oct 2012 & 5 Nov 2013 & 2 Nov 2013 & 398 & 395 & 50 & good & good & $0.93 \mathrm{~s}$ & \\
\hline RR06 & -20.6550 & 56.7639 & 4216 & 3 Oct 2012 & 7 Nov 2013 & 31 Oct 2013 & 399 & 393 & 50 & good & good & NA & \\
\hline RR07 & -20.1945 & 59.4058 & 4370 & 29 Sep 2012 & 24 Oct 2013 & 24 Oct 2013 & 389 & 389 & 50 & good & good & $0.53 \mathrm{~s}$ & \\
\hline RR08 & -19.9259 & 61.2907 & 4190 & 29 Sep 2012 & 24 Oct 2013 & 24 Oct 2013 & 389 & 389 & 50 & good & good & $1.40 \mathrm{~s}$ & \\
\hline RR09 & -19.4924 & 64.4485 & 2976 & 30 Sep 2012 & 25 Oct 2013 & 25 Oct 2013 & 389 & 390 & 50 & good & good & $2.18 \mathrm{~s}$ & \\
\hline RR10 & -19.6437 & 65.7558 & 2310 & 30 Sep 2012 & 25 Oct 2013 & 25 Oct 2013 & 390 & 390 & 50 & good & good & $0.39 \mathrm{~s}$ & \\
\hline RR11 & -18.7784 & 65.4629 & 3941 & 1 Oct 2012 & 26 Oct 2013 & 26 Oct 2013 & 390 & 390 & 50 & good & good & $0.61 \mathrm{~s}$ & \\
\hline RR12 & -18.9255 & 63.6474 & 3185 & 1 Oct 2012 & 26 Oct 2013 & 26 Oct 2013 & 390 & 390 & 50 & good & good & $-0.11 \mathrm{~s}$ & \\
\hline RR13 & -18.5427 & 60.5635 & 4130 & 2 Oct 2012 & 27 Oct 2013 & 9 Oct 2013 & 390 & 372 & 50 & good & good & NA & \\
\hline RR14 & -17.8448 & 62.5299 & 3420 & 1 Oct 2012 & 27 Oct 2013 & 27 Oct 2013 & 390 & 390 & 50 & good & good & $2.36 \mathrm{~s}$ & \\
\hline RR15 & -17.7402 & 58.3330 & 3959 & 2 Oct 2012 & 28 Oct 2013 & 4 Oct 2012 & 390 & 1 & 50 & failed & failed & NA & \\
\hline RR16 & -16.8976 & 56.5335 & 4426 & 2 Oct 2012 & 28 Oct 2013 & 28 Oct 2013 & 391 & 391 & 50 & good & good & $1.61 \mathrm{~s}$ & \\
\hline RR17 & -19.0427 & 57.1322 & 2205 & 3 Oct 2012 & 23 Oct 2013 & 23 Oct 2013 & 385 & 385 & 50 & good & good & $1.82 \mathrm{~s}$ & \\
\hline RR18 & -18.7504 & 54.8878 & 4743 & 6 Oct 2012 & 29 Oct 2013 & 29 Oct 2013 & 388 & 388 & 50 & good & good & $0.36 \mathrm{~s}$ & \\
\hline RR19 & -19.8500 & 53.3805 & 4901 & 9 Oct 2012 & 30 Oct 2013 & 30 Oct 2013 & 385 & 386 & 50 & good & good & $1.67 \mathrm{~s}$ & \\
\hline RR20 & -18.4774 & 51.4600 & 4820 & 6 Oct 2012 & 30 Oct 2013 & 30 Oct 2013 & 389 & 389 & 50 & good & good & $0.41 \mathrm{~s}$ & \\
\hline RR21 & -20.4217 & 50.5599 & 4782 & 7 Oct 2012 & 31 Oct 2013 & 31 Oct 2013 & 389 & 389 & 50 & good & good & $0.27 \mathrm{~s}$ & \\
\hline RR22 & -21.3007 & 52.4994 & 4920 & 9 Oct 2012 & 1 Nov 2013 & 1 Nov 2013 & 387 & 387 & 50 & good & good & $0.89 \mathrm{~s}$ & \\
\hline RR23 & -22.3290 & 50.4487 & 4893 & 10 Oct 2012 & 31 Oct 2013 & 26 Aug 2013 & 386 & 320 & 50 & failed & good & NA & $120 \mathrm{~s}$ inst \\
\hline RR24 & -25.6805 & 54.4881 & 5074 & 22 Oct 2012 & 3 Nov 2013 & 8 Oct 2013 & 376 & 291 & 50 & failed & good & NA & $120 \mathrm{~s}$ inst \\
\hline $\mathrm{RR} 25$ & -23.2662 & 56.7249 & 4759 & 4 Oct 2012 & 4 Nov 2013 & 4 Nov 2013 & 396 & 396 & 50 & good & good & $0.43 \mathrm{~s}$ & \\
\hline RR26 & -23.2293 & 54.4698 & 4259 & 4 Oct 2012 & 2 Nov 2013 & 2 Nov 2013 & 393 & 393 & 50 & good & good & $0.63 \mathrm{~s}$ & \\
\hline RR27 & -21.9657 & 54.2889 & 4277 & 5 Oct 2012 & 5 Nov 2013 & 19 Jul 2013 & 396 & 286 & 50 & noisy & good & NA & \\
\hline RR28 & -22.7152 & 53.1595 & 4540 & 10 Oct 2012 & 12 Nov 2013 & 12 Nov 2013 & 398 & 397 & 62.5 & good (gZ) & good & $3.10 \mathrm{~s}$ & INSU \\
\hline RR29 & -24.9657 & 51.7488 & 4825 & 11 Oct 2012 & 13 Nov 2013 & 13 Nov 2013 & 398 & 397 & 62.5 & good (gZ) & good & $3.37 \mathrm{~s}$ & INSU \\
\hline RR30 & -26.4861 & 49.8917 & 5140 & 11 Oct 2012 & 14 Nov 2013 & 8 Oct 2013 & 398 & 361 & 50 & good & good & NA & \\
\hline RR31 & -28.7648 & 48.1394 & 2710 & 12 Oct 2012 & 15 Nov 2013 & 15 Nov 2013 & 398 & 398 & 62.5 & good (gZ) & noisy & $-0.83 \mathrm{~s}$ & INSU \\
\hline RR32 & -30.2903 & 49.5555 & 4670 & 12 Oct 2012 & 15 Nov 2013 & 6 Nov 2013 & 398 & 358 & 50 & failed & good & NA & $120 \mathrm{~s}$ inst \\
\hline RR33 & -31.1170 & 50.6835 & 4904 & 13 Oct 2012 & 16 Nov 2013 & 19 Sep 2013 & 399 & 341 & 50 & noisy & noisy & NA & Geomar \\
\hline RR34 & -32.0783 & 52.2113 & 4260 & 13 Oct 2012 & 16 Nov 2013 & 16 Nov 2013 & 399 & 398 & 62.5 & good (gZ) & good & $-1.29 \mathrm{~s}$ & INSU \\
\hline RR35 & -32.9694 & 54.1473 & 4214 & 13 Oct 2012 & 17 Nov 2013 & 27 May 2013 & 399 & 225 & 50 & failed & noisy & NA & $120 \mathrm{~s}$ inst \\
\hline RR36 & -33.7018 & 55.9578 & 3560 & 14 Oct 2012 & 17 Nov 2013 & 17 Nov 2013 & 399 & 398 & 62.5 & good (gZ) & good & $3.06 \mathrm{~s}$ & INSU \\
\hline RR37 & -31.7010 & 57.8876 & 4036 & 14 Oct 2012 & 18 Nov 2013 & 19 Oct 2013 & 399 & 369 & 50 & noisy & good & NA & \\
\hline RR38 & -30.5650 & 59.6858 & 4540 & 15 Oct 2012 & 19 Nov 2013 & 19 Nov 2013 & 399 & 399 & 62.5 & good (gZ) & good & $-0.06 \mathrm{~s}$ & INSU \\
\hline RR39 & -29.0165 & 60.9755 & 4700 & 15 Oct 2012 & 19 Nov 2013 & 19 Nov 2013 & 400 & 400 & 50 & failed & noisy & NA & Geomar \\
\hline RR40 & -28.1461 & 63.3020 & 4750 & 16 Oct 2012 & 20 Nov 2013 & 20 Nov 2013 & 400 & 399 & 62.5 & $\operatorname{good}(\mathrm{gZ})$ & good & $0.19 \mathrm{~s}$ & INSU \\
\hline RR41 & -27.7330 & 65.3344 & 5430 & 16 Oct 2012 & 20 Nov 2013 & 17 Jun 2013 & 400 & 244 & 100 & good & good & NA & \\
\hline RR42 & -27.6192 & 65.4376 & 4776 & 16 Oct 2012 & 21 Nov 2013 & 10 Aug 2013 & 400 & 298 & 50 & failed & good & NA & $120 \mathrm{~s}$ inst \\
\hline RR43 & -27.5338 & 65.5826 & 4264 & 16 Oct 2012 & 21 Nov 2013 & 15 Jun 2013 & 401 & 241 & 100 & good & good & NA & \\
\hline RR44 & -27.5324 & 65.7480 & 4548 & 16 Oct 2012 & 22 Nov 2013 & 3 Jun 2013 & 401 & 229 & 100 & good & good & NA & \\
\hline RR45 & -27.6581 & 65.6019 & 2822 & 16 Oct 2012 & 21 Nov 2013 & 4 Jun 2013 & 400 & 138 & 100 & noisy & good & NA & \\
\hline
\end{tabular}


Table 3. Continued.

\begin{tabular}{|c|c|c|c|c|c|c|c|c|c|c|c|c|c|}
\hline $\begin{array}{l}\text { Station } \\
\text { name }\end{array}$ & Latitude & Longitude & $\begin{array}{l}\text { Depth } \\
{[\mathrm{m}]}\end{array}$ & $\begin{array}{l}\text { Deployment } \\
\text { date } \\
\text { [UTC] }\end{array}$ & $\begin{array}{l}\text { Recovery } \\
\text { date } \\
\text { [UTC] }\end{array}$ & $\begin{array}{l}\text { End of } \\
\text { record } \\
{[\mathrm{UTC}]}\end{array}$ & $\begin{array}{l}\text { Install. time } \\
\text { [days] }\end{array}$ & $\begin{array}{l}\text { Record } \\
\text { length } \\
\text { [days] }\end{array}$ & s.r. $[\mathrm{Hz}]$ & $\begin{array}{l}\text { Seismo } \\
\text { status }\end{array}$ & $\begin{array}{l}\text { Hydro } \\
\text { status }\end{array}$ & $\begin{array}{l}\text { Skew } \\
\text { value }\end{array}$ & Notes \\
\hline RR46 & -27.7909 & 65.5835 & 3640 & 16 Oct 2012 & 21 Nov 2013 & 26 May 2013 & 400 & 221 & 100 & good & good & NA & \\
\hline RR47 & -27.6958 & 65.7553 & 4582 & 16 Oct 2012 & 21 Nov 2013 & 22 Jun 2013 & 400 & 248 & 100 & good & good & NA & \\
\hline RR48 & -27.5792 & 65.9430 & 4830 & 16 Oct 2012 & 22 Nov 2013 & 10 Jun 2013 & 401 & 237 & 100 & good & good & NA & \\
\hline RR49 & -26.2742 & 68.5354 & 4444 & 17 Oct 2012 & 23 Nov 2013 & 6 Nov 2013 & 401 & 384 & 50 & failed & good & NA & $120 \mathrm{~s}$ inst \\
\hline RR50 & -25.5181 & 70.0222 & 4100 & 18 Oct 2012 & 23 Nov 2013 & 23 Nov 2013 & 401 & 400 & 62.5 & $\operatorname{good}(\mathrm{gZ})$ & good & $1.74 \mathrm{~s}$ & INSU \\
\hline RR51 & -22.9989 & 69.1911 & 3463 & 18 Oct 2012 & 24 Nov 2013 & 3 Jan 2013 & 401 & 76 & 50 & failed & failed & NA & $120 \mathrm{~s}$ inst \\
\hline RR52 & -20.4722 & 68.1094 & 2880 & 19 Oct 2012 & 25 Nov 2013 & 25 Nov 2013 & 401 & 401 & 62.5 & good (gZ) & good & $0.97 \mathrm{~s}$ & INSU \\
\hline RR53 & -20.1213 & 64.9664 & 2940 & 20 Oct 2012 & 28 Nov 2013 & 30 Oct 2013 & 403 & 375 & 50 & good & good & NA & Geomar \\
\hline RR54 & -20.6424 & 63.5082 & 2499 & 20 Oct 2012 & 28 Nov 2013 & 21 Oct 2013 & 404 & 365 & 50 & failed & good & NA & $120 \mathrm{~s}$ inst \\
\hline RR55 & -21.4417 & 61.4959 & 4462 & 20 Oct 2012 & 28 Nov 2013 & 8 Nov 2013 & 404 & 383 & 50 & good & good & NA & \\
\hline RR56 & -21.9694 & 59.5853 & 4230 & 21 Oct 2012 & 29 Nov 2013 & 29 Jun 2013 & 404 & 251 & 50 & good & good & NA & Geomar \\
\hline RR57 & -24.7264 & 58.0496 & 5200 & 21 Oct 2012 & 3 Nov 2013 & 31 Oct 2013 & 378 & 374 & 50 & failed & good & $1.28 \mathrm{~s}$ & $120 \mathrm{~s}$ inst \\
\hline
\end{tabular}

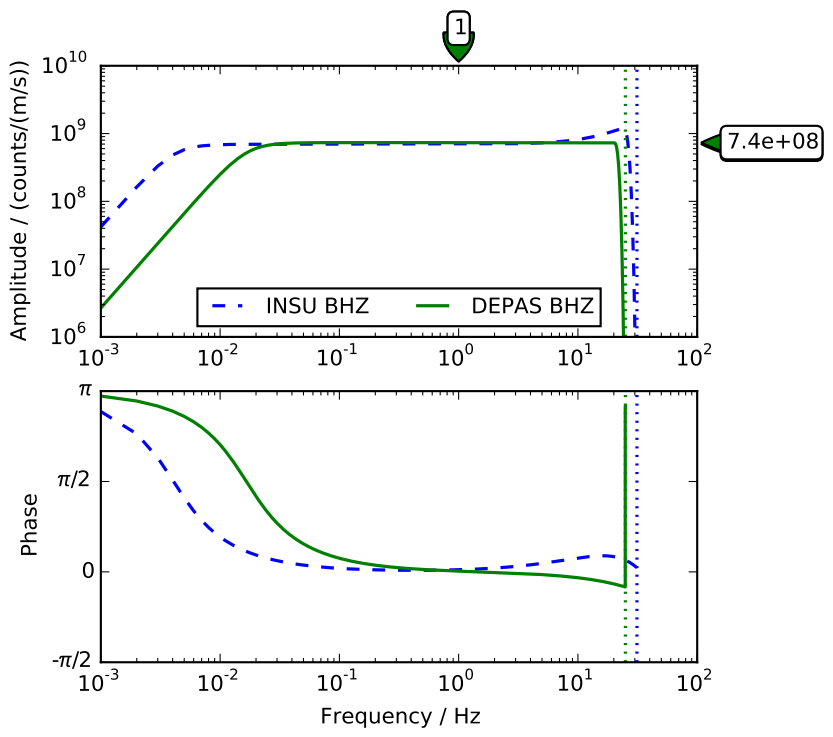

Figure 4. Bode plot of the total instrument responses $G(f)$ as defined in Eq. (A2) of vertical seismometer components, for a DEPAS Güralp CMG-OBS40T seismometer (solid green, station RR26), and for an INSU Trillium-240 (dashed blue, RR28). The corner period is $60 \mathrm{~s}$ for DEPAS instruments and $240 \mathrm{~s}$ for INSU instruments, which is evident from the amplitude responses. Horizontal channel responses of DEPAS instruments are identical to vertical responses, apart from the channel-specific gain, which varies by a few percent. The horizontal gain of INSU sensors is $1.6 \times 10^{8}$ counts $\left(\mathrm{m} \mathrm{s}^{1}\right)^{-1}$ compared to of $7.0 \times 10^{8}$ counts $\left(\mathrm{m} \mathrm{s}^{1}\right)^{-1}$ for the vertical channel. The upper frequency limits (dotted lines) are given by the Nyquist frequencies $(1 / 2 \times 50 \mathrm{~Hz}$ for RR26 and $1 / 2 \times 62.5 \mathrm{~Hz}$ for RR28).

\subsection{Instrument failures}

Three out of 48 DEPAS stations (RR02, RR04, RR15) delivered neither seismometer nor hydrophone data because their data loggers failed (reason unclear). The seismometers in nine DEPAS stations (RR23, RR24, RR32, RR35, RR42, RR49, RR51, RR54, RR57) featured a redesigned sen-

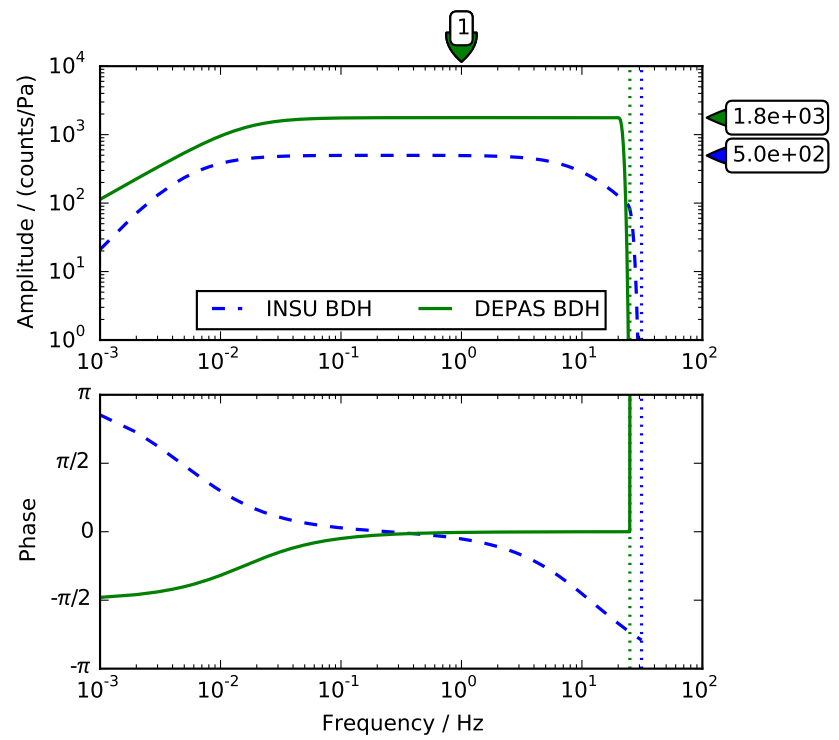

Figure 5. Bode plot of the total instrument responses $G(f)$ as defined in Eq. (A2) of a DEPAS HighTechInc HTI-PCA04/ULF hydrophone (solid green, station RR26), and of an INSU differential pressure gauge (dashed blue, RR28). The nominal corner period is $100 \mathrm{~s}$ for DEPAS instruments and $500 \mathrm{~s}$ for INSU instruments. Dotted lines mark the Nyquist frequencies (see above).

sor/casing package with broader band CMG-OBS40T sensors $(120 \mathrm{~s})$, which had previously not been deployed in the deep sea. The levelling mechanisms failed (remained stuck) in all nine stations, for reasons that are still under investigation. Automatic, prolonged attempts to level the sensors drained their batteries prematurely so that the functioning hydrophones also ran out of power 8-9 months into the experiment. DEPAS seismometers RR27 and RR45 recorded, but at high noise levels (reason under investigation). The hydrophones of these stations worked normally. The seismometer in one of the four Geomar stations failed (RR39), and noise levels at Geomar station RR33 are unusually high, al- 

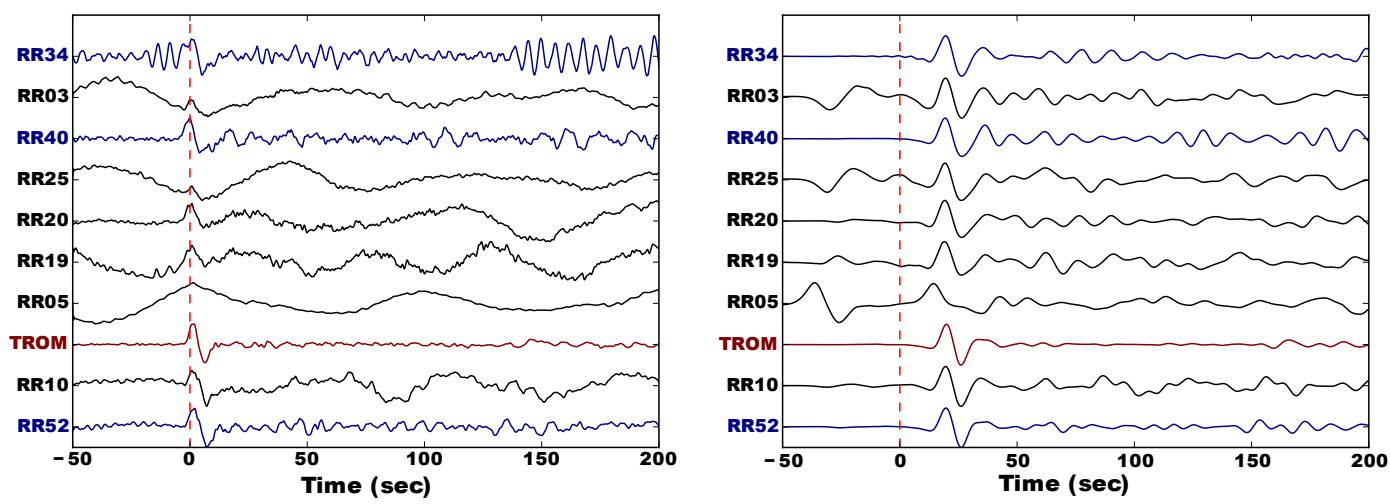

Figure 6. Comparison of broadband (left panel) and bandpass-filtered seismograms for six DEPAS OBS (black), three INSU OBS (RR34, RR40, RR52, blue) and an island station (TROM on Île Tromelin, red) in the northern part of the OBS network (see Fig. 1). All seismograms have been instrument-corrected to displacement, filtered between 1/60 and $3 \mathrm{~Hz}$ (the nominal corner frequencies of the least broadband sensor type, the DEPAS OBS) in order to facilitate visual comparison. The waveforms on the right have been bandpass-filtered using a Gabor filter as described in Sigloch (2008, p. 100) with a centre frequency of 1/15 Hz. Waveforms are amplitude-normalized and plotted relative to the theoretical arrival time of a P-wave from a magnitude 6.6 earthquake on 20 April 2013 in Sichuan, China ( $71^{\circ}$ distance, see GEOFON, 2013). This shows that the instrument response has been determined correctly and that even the relatively noisy DEPAS recordings can be used for purposes like waveform tomography. The band-pass filter strongly enhances the P-wave, compared to the wideband traces, where it is lost in the long period noise for most DEPAS stations.

though this might not be due to the sensor. The hydrophones in RR33 and RR39 measured, but at a high noise level.

The 9 INSU stations (RR28, RR29, RR31, RR34, RR36, RR38, RR40, RR50, RR52) were affected by a bug in the data logger software that activated the level-sensing circuitry every $3620 \mathrm{~s}$ (roughly every hour). Each such event caused a "glitch" in the seismograms of roughly $1200 \mathrm{~s}$ duration, i.e. a characteristic, complex pulse shape, that is very similar but not identical across events. Pulse amplitudes are between 500-800 counts, corresponding to $1.5 \mu \mathrm{m}$ ground displacement after instrument correction and filtering between 20 and $500 \mathrm{~s}$ period. This artefact is rarely visible on horizontal components where noise levels are much higher in this period band, but it exceeds noise amplitudes on the vertical channels by $15 \mathrm{~dB}$. Figure 8 shows that the glitch amplitude is comparable to body wave arrivals of intermediate-size, teleseismic earthquakes, here a $M 6.6$ earthquake at $71^{\circ}$ distance. Efforts are under way to suppress this artefact by matched filtering.

The differential pressure gauge in INSU station RR31 had high artefacts roughly every $9000 \mathrm{~s}$. Seismic signals are visible in between, but may be difficult to use. For station RR38, gaps in the data had to be fixed. Although this was carefully done, it is possible that artefacts were introduced.

\subsection{Estimation of clock error}

The internal clocks of the data recorders are affected by drifts on the order of one second per year. Over 13 months of autonomous recording, drift of this magnitude is nonnegligible for certain applications, such as body-wave tomography. Prior to deployment, each recorder clock was synchronized to GPS, and upon recovery it was compared to
GPS time again, yielding the clock drift or "skew". Assuming that the skew accumulated linearly over the deployment period, the clock error can be corrected for any moment in time. Previous studies (Hannemann et al., 2014; Scholz, 2014) show that linearity is a good first order approximation for the clocks used in the DEPAS instruments. For the LCPO2000 instruments used in the INSU pool, Gouedard et al. (2014) found that drift rates can vary over the course of days. We assume that this effect is cancelling out for longer deployments, therefore RHUM-RUM data at the RESIF data centre are linearly corrected for skew, where available.

Unfortunately a significant number of DEPAS clocks stopped before recovery, so that the skew could not be measured (entries "NA" in Table 3). Clock shutdown was not anticipated even if batteries became weak. At a critical voltage level of $6.0 \mathrm{~V}$ (down from $13.0 \mathrm{~V}$ ), the recorder was programmed to switch off seismometer and hydrophone, allowing its low-consuming clock to continue for several months. The Lithium batteries for long-term deployments have a faster current drop than the alkali batteries for normal deployments, which caused a problem for multiple stations. Superimposed on a gradual voltage decline, the log files show brief, steep voltage drops associated with levelling events every 21 days. Towards the end of the recording period, this led to uncontrolled shutdown of some recorders and clocks, presumably when a drop below critical voltage occurred too suddenly.

Using cross-correlation of ambient noise, SensSchönfelder (2008) presented a method to determine the relative clock error between two seismometers a posteriori, which Hannemann et al. (2014) successfully applied to OBS data. Likewise, Scholz (2014) succeeded in estimating 

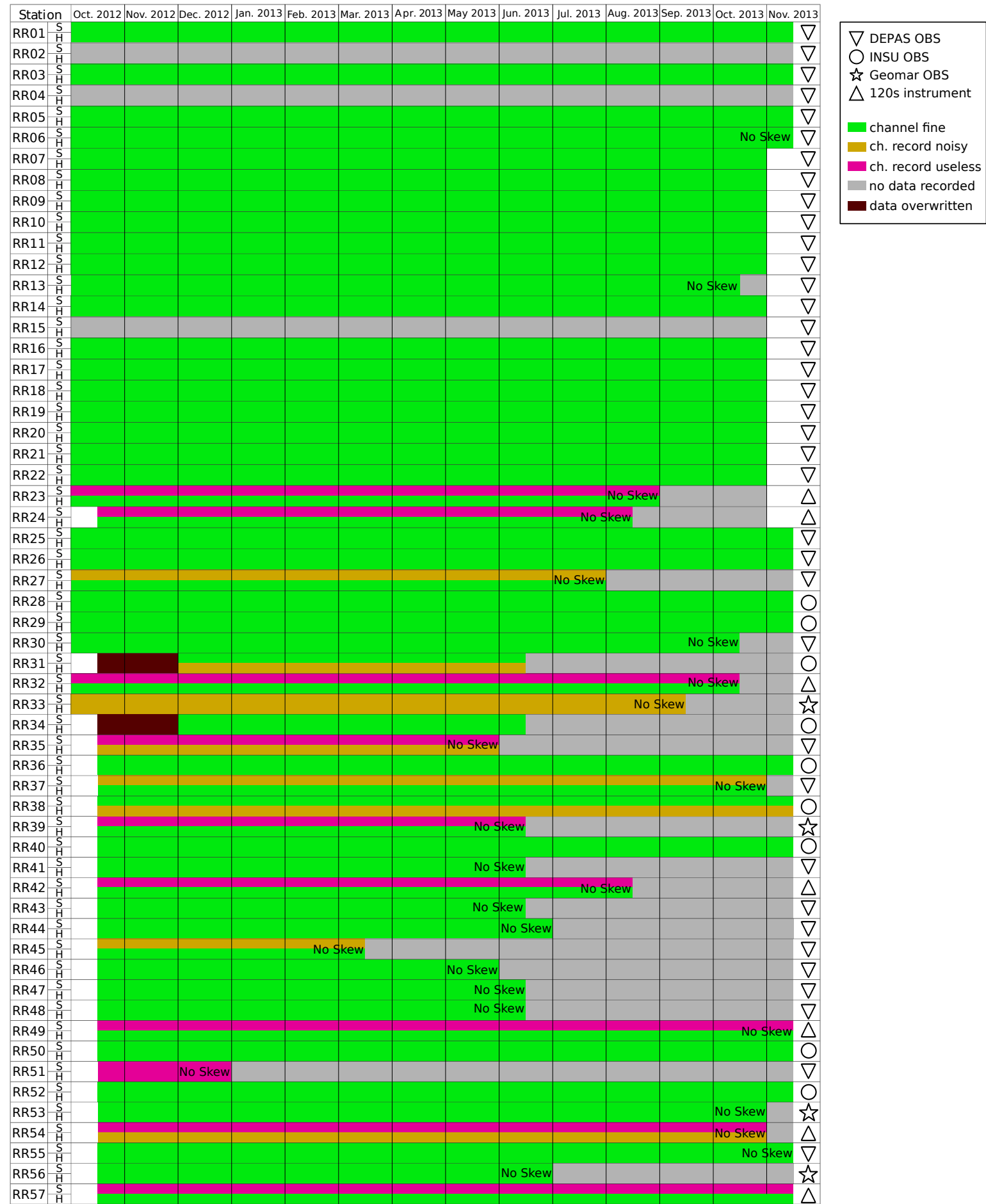

channel fine

ch. record noisy

no data reco

Figure 7. Data availability and quality for all RHUM-RHUM ocean-bottom stations. Green indicates availability of good data. Yellow indicates availability of abnormally noisy data, where earthquakes are visible, but artefacts are so strong, that noise correlation or other advanced analyses will probably fail. Red indicates that the seismometer ("S" in first column) or hydrophone/differential pressure gauge ("H") recorded data that is completely useless for seismological purposes. These time traces will still be archived at RESIF and may be useful for analysis of error sources. Grey shading indicates time intervals when battery power had run out prior to recovery, or where the data logger failed (RR02, RR04, RR15) and no data was recorded at all. Dark red shading indicates time intervals of missing data for INSU stations RR31 and RR34 (overwritten due to erroneous reset of data logger). Station symbols in the last column follow Fig. 1. Inverted Triangles: regular DEPAS LOBSTER (seismometer $60 \mathrm{~s}$ corner period, $50 \mathrm{~Hz}$ sampling rate); stars: Geomar LOBSTER (60 s, $50 \mathrm{~Hz}$ ); regular triangles: newer DEPAS LOBSTER (120 s corner period, all seismometers failed); circles: INSU/Scripps instrument (240 s, $62.5 \mathrm{~Hz})$. 


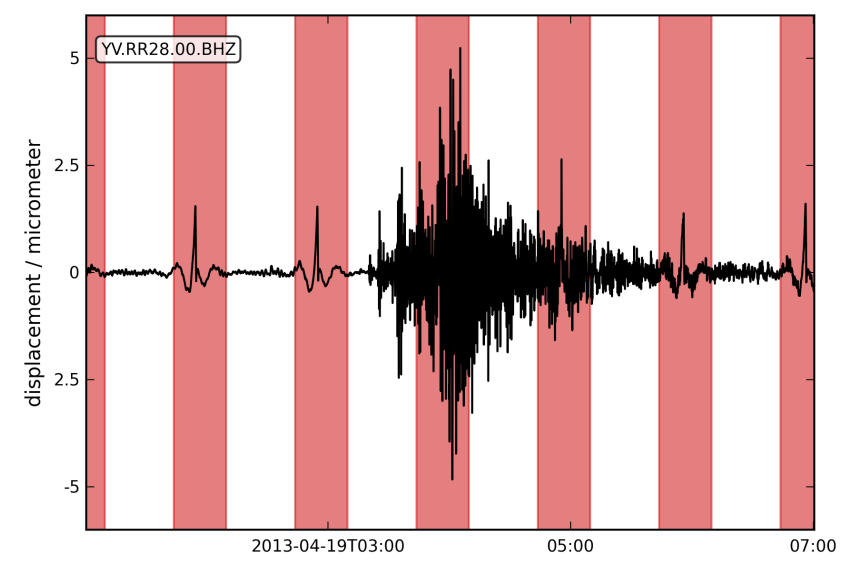

Figure 8. A $M 6.6$ earthquake at $71^{\circ}$ distance recorded on the vertical component of INSU OBS RR28. The seismogram has been instrument-corrected to ground displacement and passband-filtered at 20 to $500 \mathrm{~s}$. One red plus one white stripe span $3620 \mathrm{~s}$, slightly more than one hour. The seismogram shows one "glitch" per red shaded interval, i.e. nearly hourly, pulse-like artefacts caused by unintended activation of the sensor levelling mechanism in INSU stations. One glitch is hidden by the surface wave train. The earthquake is the same as in Fig. 6 (66 distance, see GEOFON, 2013).

clock drift for the SWIR sub-array of the RHUM-RUM network (RR42-RR48, inter-station distances of 30-40 km). His results suggest that indeed clock errors accumulated linearly over the installation period. For the remainder of the RHUM-RUM network, inter-station distances were unfortunately found to be too large ( $>150 \mathrm{~km}$ ) to apply this ambient noise method, especially given the high self-noise level of the DEPAS OBS packages.

In an attempt to estimate the clock drift of these 11, otherwise well-functioning OBS a posteriori, we did a dry run of several recorders in the DEPAS lab with batteries and seismometers attached for over a month. Afterwards, we compared the value of the internal clock with GPS time. These experiments reproduced the sign of the clock error (clocks generally ran too slow) but probably not their values, at least not to an accuracy that would be useful in practice. The likely reason is that we did not simulate the low water temperatures on the seafloor. The experiment is described in detail in Appendix B.

\subsection{Noise levels}

Noise levels can be characterized by Probabilistic Power Spectral Density distributions (PPSDs, McNamara and Buland, 2004) for each of the four sensor components. We obtain PPSDs by computing power spectra on hour-long broadband time series, and by stacking the hourly results over the recording period. Figure 9 shows PPSDs for DEPAS station RR26 (depth $4259 \mathrm{~m}$ ) and for INSU station RR28 (depth $4540 \mathrm{~m}$ ), which were deployed at $150 \mathrm{~km}$ distance between each other.
We created a poster of PPSDs for all 57 stations and all 4 channels, which is published as a Supplement to this article and shows that the relative noise differences of Fig. 9 are characteristic for INSU versus DEPAS stations more generally.

\subsubsection{Vertical seismometer channels}

The seismometer spectra are rather similar at short periods but increasingly divergent at periods longer than $5 \mathrm{~s}$. The vertical channel (BHZ) of the INSU instrument has its low-noise notch at 10-30 s period and stays well below the bounds of the (terrestrial) New High Noise Model (Peterson, 1993), to periods longer than $200 \mathrm{~s}$. The BHZ channel of the DEPAS instrument has its low-noise notch around 10-15 s; at longer periods, the noise rapidly increases, rising well above the Peterson High Noise Model.

At $40 \mathrm{~s}$ period, the noise level on the BHZ channel is around $-125 \mathrm{~dB}$ for DEPAS instruments and $-155 \mathrm{~dB}$ for INSU instruments. These values are before correction for tilt or sea floor compliance (Crawford and Webb, 2000). At periods longer than $20 \mathrm{~s}$, noise levels on BHZ show little amplitude variation over the deployment period, with a variance of roughly $10 \mathrm{~dB}$ at most stations (Fig. 9).

\subsubsection{Horizontal seismometer channel}

Noise on the horizontal seismometer channels is much higher than on the vertical for both instrument types. Horizontal components show mean noise levels between -100 and $-115 \mathrm{~dB}$ for DEPAS OBS, and around $-135 \mathrm{~dB}$ for INSU instruments (at $40 \mathrm{~s}$ period). The variance is on the order of $20 \mathrm{~dB}$ and shows clear seasonal variations (Fig. 10).

Tilting of the instrument, e.g. caused by underwater currents shaking the OBS frame (Duennebier et al., 1981; Trehu, 1985; Webb, 1998) affects the horizontal channels much more than the vertical component, so the higher horizontal noise level is expected.

\subsubsection{Hydrophone channel}

The spectra of DEPAS hydrophones and INSU differential pressure gauges are rather similar across the entire frequency range, both in general shape and in absolute decibel levels (see Figs. 9, C1, C2 and C3). This is in marked contrast to the large differences in seismometer noise levels between DEPAS and INSU instruments, and again points to a tilt origin or self-noise for the DEPAS seismometer noise, since tilt would hardly affect hydrophone records.

The pressure noise at DEPAS hydrophone RR26 is even slightly lower than at the near-by INSU RR28 (Fig. 9). In general, hydrophone noise levels are approximately $5 \mathrm{~dB}$ lower on DEPAS stations than on INSU stations in the period range of $12-40$ s (see Fig. C2 in the appendix). This is true for the DEPAS hydrophones in general, with the exception of only a few noisy outliers that had individual problems. The 


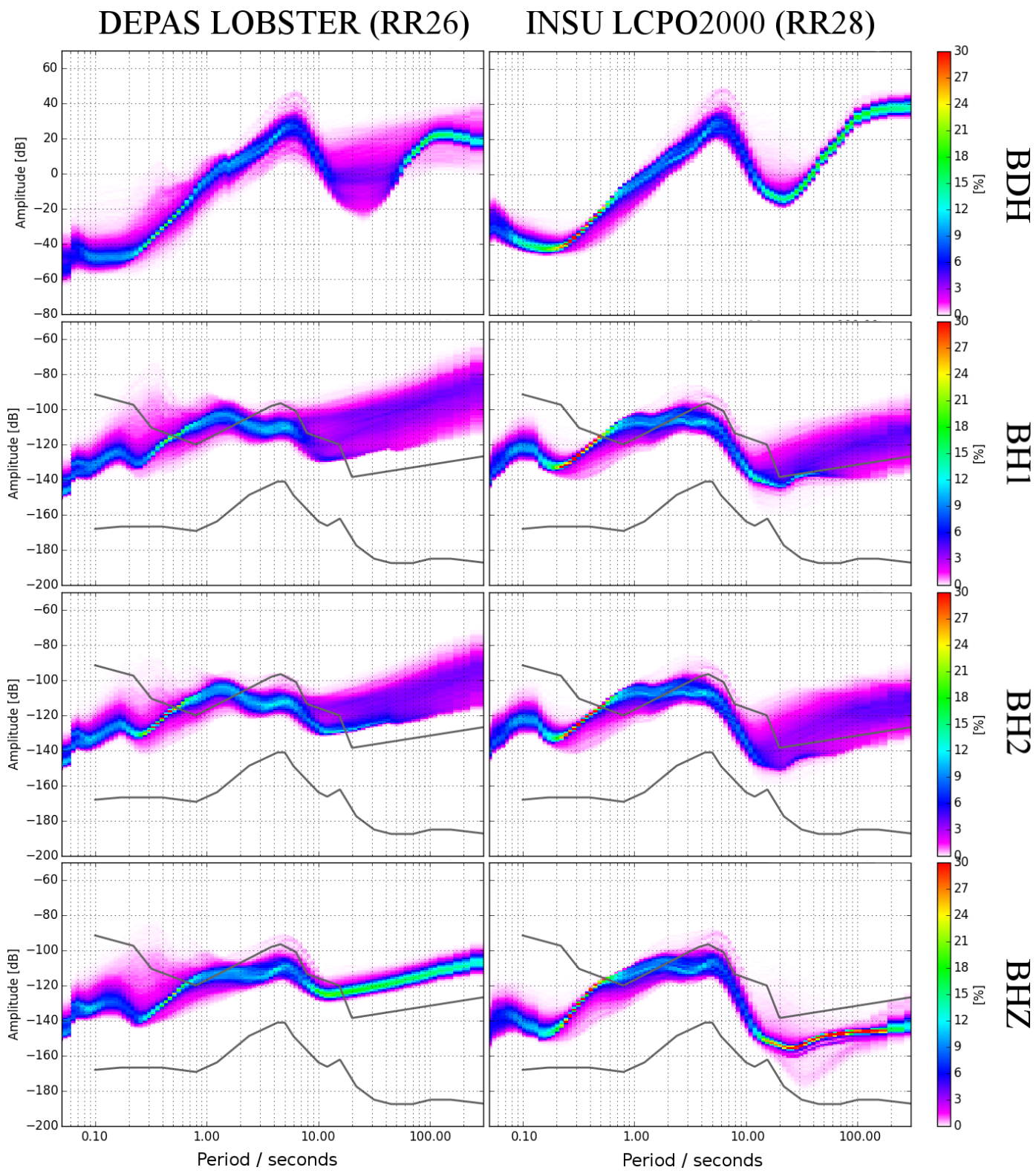

Figure 9. Probabilistic power spectral densities (PPSDs) for a DEPAS station (RR26, left column panels) and an INSU station (RR28, right column panels). PPSDs are composed of hour-long power spectra stacked over the entire deployment interval. Colour marks the frequency of occurrence of different noise levels, where purple indicates relatively rare, and red relatively frequent (McNamara and Buland, 2004). Black curves mark the upper and lower bounds of the New High and Low Noise Model of Peterson (1993). The two instruments were installed within $150 \mathrm{~km}$ of each other, in an abyssal plain $300 \mathrm{~km}$ south-west of La Réunion island (cf. Fig. 1). At periods longer than $5 \mathrm{~s}$, the INSU seismometers are much quieter than the DEPAS instrument (see Sect. 4). By contrast, the pressure channel BDH of the two models (hydrophone for DEPAS, differential pressure gauge for INSU) shows very similar noise levels. A poster with PPSDs for all stations is available on ResearchGate (Stähler et al., 2015) and as an Supplement to this paper.

overall lower noise level can probably be explained by completely different instrument types (hydrophones on DEPAS versus differential pressure gauges on INSU stations).

\subsection{Temporal noise variations}

We expect two sources for temporal noise variations: (1) varying wave heights due to storm activity, which affects mostly the microseismic noise band. (2) Water currentinduced tilt, which creates long period noise. 
Figure 10 shows the temporal evolution of noise levels between October 2012 and October 2013 at DEPAS station RR01 near La Réunion (depth $4298 \mathrm{~m}$ ), between 2 and $60 \mathrm{~s})$. In the secondary microseismic noise band $(2-10 \mathrm{~s}$ period), peak noise intervals coincide with cyclone passages during southern summer (blue frames). Cyclones are tropical storms, the Indian Ocean equivalent of hurricanes and typhoons. Their correlation to microseismic noise is most pronounced on the BHZ component. In fact, Davy et al. (2014) were able to track the path of a cyclone across the RHUMRUM network using recordings of secondary microseismic noise only.

By contrast, peak noise episodes in the 20-60 s band show no clear correlation with cyclone passages. Rather, the highest levels occur during southern winter (March to September), out of cyclone season. Seasonal variations in deepsea currents might explain tilt noise at these lower frequencies. The HYCOM-based global ocean circulation model (GLBa 0 .08/expt_90.9) (Cummings, 2005) does predict more episodes of strong currents at RR01 during southern autumn, (Fig. 10 bottom), but its absolute velocity values would appear low for effectively shaking an OBS. However, global ocean circulation models for this region have very poor resolution in the bottom layer, so that true bottom currents may be different. A recent measurement of current profiles at $23^{\circ} \mathrm{S}$, $48^{\circ} \mathrm{E}$ (Ponsoni et al., 2015) suggests that bottom velocities generally do not exceed a few $\mathrm{cm}$ per second in the region (L. Ponsoni, personal communication, 2015). Unfortunately, the nearest RHUM-RUM station, (RR23) failed to deliver seismograms for comparison.

\section{Discussion of the different noise levels}

The relative stronger overall noise on the DEPAS instrument affects the usability of the OBS for waveform tomography and analysis of long-period waveforms. Hence its causes are of interest to future users of the pool and for instrument developers. We discuss four potential differences between the two instrument types:

The gimbal system: if the gimbal system were not stable enough, it could cause additional noise on all components. This hypothesis cannot be proven or falsified, since the CMG-OBS40T cannot be tested outside its gimbal. Experience shows that this would rather cause high-frequency noise.

The data logger: the data loggers of the DEPAS and the INSU OBS could have different self-noise levels. Again, this cannot be tested, since we have no data from other loggers available. But similar to the gimbal system, this would rather affect the high-frequency end of the spectrum, which is similar for both types.

OBS tilt: the integration of the seismometer into the OBS frame makes the DEPAS instruments more susceptible

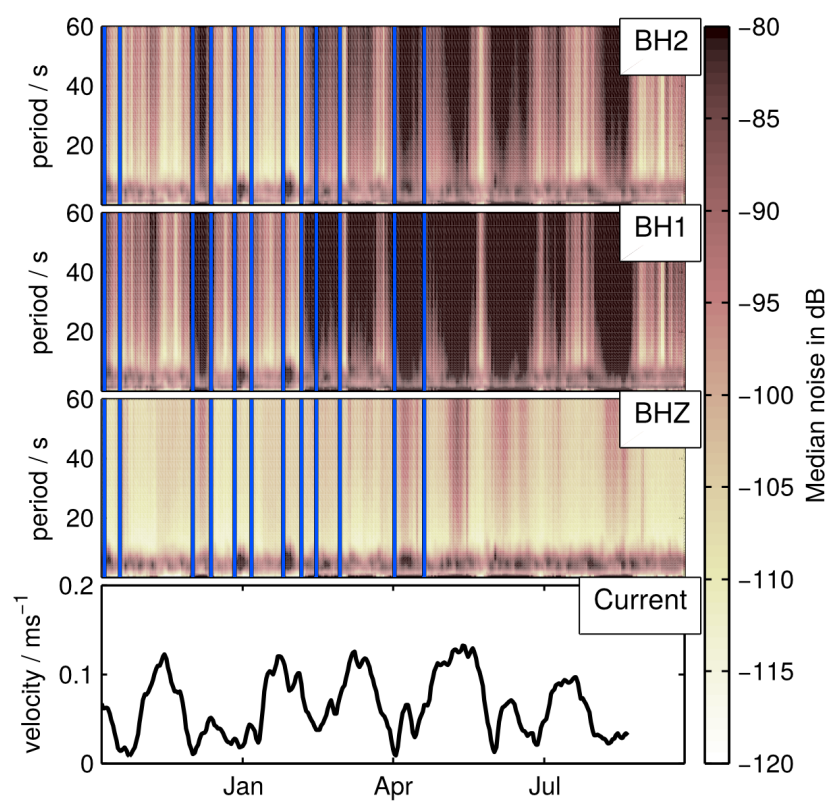

Figure 10. Seasonal changes in the noise levels on OBS RR01 near La Réunion. Spectrograms of noise on the three seismometer components, where noise is plotted as the median of daily probabilistic power spectral densities. Blue boxes mark episodes of cyclone activity, which correlates well with peak noise episodes in the microseismic band (periods around $10 \mathrm{~s}$ ), especially on the BHZ component. At periods longer than $20 \mathrm{~s}$, seismic noise peaks occur preferentially in southern autumn (February-June), most evident on the horizontal components. The global ocean circulation model HYCOM GLBa0.08/expt_90.9, running from 3 January 2011 to $20 \mathrm{Au}-$ gust 2013 predicts more intervals of strong ocean-bottom currents for southern autumn (bottom panel) - qualitatively consistent with the hypothesis that ocean bottom currents cause long-period OBS noise by tilting the seismic sensors.

to current-induced tilt. Seasonal variations on the noise level of the horizontal channels can be seen in Fig. 10 and in the cloudy look of the PPSDs beyond $10 \mathrm{~s}$ in Fig. 9. However, tilt noise should affect horizontal channels much more strongly than vertical ones, which is indeed the case for the INSU instruments. For the DEPAS instruments, the vertical noise is too high to be explained by tilt alone.

Seismometer self noise: the CMG-OBS40T is a 60s wideband instrument, based on the $10 \mathrm{~s}$ CMG-40T. While the self noise of the latter is below the New Low Noise Model (NLNM) for periods shorter than 10s, onshore experiments with one of the CMG-OBS40Ts showed self noise of $-140 \mathrm{~dB}$ at $10 \mathrm{~s}$ period, which is far above the NLNM. This strongly suggests that the reduced power consumption of the OBS40T comes at the price of a significantly increased self-noise level. High selfnoise probably explains the larger part of the excessive noise on the vertical channel in our experiment. 
To summarize, we expect the high noise level of the DEPAS instruments to be caused by a combination of tilt and instrument self noise, where the former dominates the noise on the horizontal channels and the latter the noise on the vertical channel. The fact that the variability of noise on the horizontal channels is comparable between the two instrument types suggests that the susceptibility to currents is similar, albeit slightly higher on the DEPAS instrument package. The usage of a compact wideband sensor in the LOBSTER instruments has the advantage of a much lower power consumption, at the price of a strongly increased noise level beyond $10 \mathrm{~s}$.

More detailed analysis of the effect of sensor integration would require usage of a more broadband sensor in the DEPAS instrument package.

\section{Conclusions}

From October 2012 to November 2013, the RHUM-RUM experiment deployed and successfully recovered 48 German DEPAS and 9 French INSU broadband ocean-bottom seismometers around La Réunion, western Indian Ocean, making this the largest deployment of either instrument type, and the only joint experiment. Overall network performance was very satisfactory, but a number of technical issues have been described here, including blocked levelling mechanisms, data logger malfunctioning, and loss of clock synchronization.
For the first time, we publish instrument response information on the DEPAS OBS, which allows to calculate the true ground displacement in a wide frequency range.

This shows that at periods longer than $10 \mathrm{~s}$, the INSU OBS are much quieter than the DEPAS instruments, on all three seismometer components. No such difference in data quality exists for the hydrophones and differential pressure gauges, which both worked extremely reliably. The increased longperiod noise on the DEPAS seismometers can be explained by the surprisingly high instrument self-noise on the all channels of the Güralp CMG-OBS40T sensors and partially by a higher susceptibility to current-induced tilt of the whole OBS.

In the microseismic noise band, peak noise intervals can be attributed to tropical storm activity (cyclones), whereas no clear correlation with cyclones was found at lower frequencies, where tilt and self-noise dominates (20-60 s period band). A possible cause for instrument tilt is the action of ocean-bottom currents, which are predicted to peak in southern winter just like the tilt noise, but global ocean circulation models are not sufficiently constrained to test this hypothesis in more detail.

The RHUM-RUM data set has been assigned FDSN network code YV and will be freely available by the end of 2017. Data and detailed StationXML meta-data files are hosted and served by the RESIF data centre in Grenoble (http://portal.resif.fr/?RHUM-RUM-experiment\&lang=en). 


\section{Appendix A: Instrument responses}

While conceptually straightforward, instrument corrections can be non-trivial in practice because filter description can be complex, and their specifications must exactly match the format expected by the software used to apply the corrections.

\section{A1 Seismometers}

Assuming that the seismometer is a causal linear timeinvariant system, its response can be described by a series of poles $p_{m}$ and zeros $r_{n}$ :

$G_{\text {inst }}(f)=S_{\text {d,inst }} \cdot A_{0} \cdot \frac{\prod_{n=1}^{N}\left(2 \pi i f-r_{n}\right)}{\prod_{m=1}^{M}\left(2 \pi i f-p_{m}\right)}$.

In Eq. (A1), $S_{\text {d,inst }}$ is the sensitivity at reference frequency $f_{\mathrm{r}}$ with dimension counts $\left(\mathrm{ms}^{-1}\right)^{-1}$. $A_{0}$ is a dimensionless normalization constant, which normalizes $G(f)$ to 1 at reference frequency $f_{\mathrm{r}}$. Following convention, we defined $f_{\mathrm{r}}=1 \mathrm{~Hz}=(2 \pi)^{-1}\left(\mathrm{rad} \mathrm{s}^{-1}\right)$. The $M$ poles $p_{m}$ and $N$ zeros $r_{n}$ describe the frequency-dependency of the response.

Values for each instrument can be queried sending its serial number email to caldoc@guralp.com. Note that these data sheets contain the frequencies of the poles and zeros in $\mathrm{Hz}$, while the StationXML format prefers them in $\mathrm{rad} \mathrm{s}^{-1}$. All DEPAS seismometers that functioned had the same $M=4$ poles and $N=2$ zeros as described in Table A1a, with the exception of RR13 that had $M=5$ (Table A1b) and RR22 with $M=6$ poles (Table A1c) ${ }^{1}$.

Poles and zeros characterize the first, analogue stage of an instrument; subsequent digital filter stages characterize the ADC (Analogue to Digital Converter) and digital processing units of the data recorder. For the seismometers, the analogue filter stages were obtained from the manufacturers Güralp and Nanometrics, and are compared in Fig. 4.

We follow the SEED reference manual's Appendix C (Ahern et al., 2012) to describe the response $G(f)$ in frequencydomain. The total transfer function is the product of complex response functions for the instrument, ADC and FIR decimation stages:

$G(f)=G_{\text {inst }}(f) \cdot G_{\mathrm{ADC}}(f) \cdot G_{\mathrm{FIR}}(f)$.

The gain or sensitivity $S_{\mathrm{d} \text {,inst }}$ is channel specific and is determined by Güralp before delivering the instrument. For our instruments, a typical value is $1980 \mathrm{~V}\left(\mathrm{~ms}^{-1}\right)^{-1}$ with an instrument-specific variance of $15 \mathrm{~V}\left(\mathrm{~ms}^{-1}\right)^{-1}$.

The analogue seismometer signal was converted to digital counts by a SEND GEOLON-MCS data logger. This conversion is assumed to have a flat response curve:

\footnotetext{
${ }^{1}$ For the $120 \mathrm{~s}$ instruments, the manufacturer lists the same 6 poles and 2 zeros as RR22, which is probably not correct, since they describe a corner period of $60 \mathrm{~s}$. But since none of those recorded data, this should not be a problem to users of the data.
}

Table A1. (a) 4 poles and 2 zeros of the $60 \mathrm{~s}$ Güralp CMG-OBS40T used in the German LOBSTER OBS. Can be applied to all 60 s stations but RR13 and RR22. (b) 5 poles and 2 zeros of the $60 \mathrm{~s}$ Güralp CMG-OBS40T used in station RR13. (c) 6 poles and 2 zeros of the 60 s Güralp CMG-OBS40T used in station RR22. (d) 11 poles and 6 zeros of the Trillium 240OBS used in the French OBS at RR38, RR50 and RR52. (e) 11 poles and 6 zeros of Trillium 240OBS with a serial number below 400. Those were used in stations RR28, RR29, RR31, RR34, RR36 and RR40.

\begin{tabular}{|c|c|c|}
\hline & $\begin{array}{l}\text { Pole } p_{m} \\
\text { in rad s}\end{array}$ & $\begin{array}{c}\text { Zero } r_{n} \\
\text { in } \operatorname{rad~s}^{-1}\end{array}$ \\
\hline \multicolumn{3}{|c|}{ (a) } \\
\hline $1 / 2$ & $-0.074016 \pm 0.07347 i$ & 0 \\
\hline $3 / 4$ & $-502.65 \pm 596.9 i$ & - \\
\hline \multicolumn{3}{|c|}{ (b) } \\
\hline $1 / 2$ & $-0.074016 \pm 0.074016 i$ & 0 \\
\hline 3 & -502.66 & - \\
\hline 4 & -1005.3 & - \\
\hline 5 & -1130.98 & - \\
\hline \multicolumn{3}{|c|}{ (c) } \\
\hline $1 / 2$ & $-0.074016 \pm 0.074016 i$ & 0 \\
\hline 3 & -471.24 & - \\
\hline $4 / 5$ & $-395.1 \pm 850.69 i$ & - \\
\hline 6 & -2199.1 & - \\
\hline
\end{tabular}

\begin{tabular}{llc}
\hline \multicolumn{1}{c}{$(\mathbf{c})$} \\
\hline $1 / 2$ & $-0.018134 \pm 0.018034 i$ & 0 \\
3 & -84.4 & -72.5 \\
4 & $-180.2+224.4 i$ & -163.3 \\
5 & $-180.2-224.4 i$ & -251 \\
6 & -725 & -3270 \\
7 & -1060 & - \\
8 & -4300 & - \\
9 & -5800 & - \\
$10 / 11$ & $-4200 \pm 4600 i$ & - \\
\hline
\end{tabular}

\begin{tabular}{llc}
\hline \multicolumn{2}{c}{$(\mathbf{e})$} \\
\hline $1 / 2$ & $-0.017699 \pm 0.017604 i$ & 0 \\
3 & -85.3 & -72.5 \\
4 & $-155.4+210.8 i$ & -159.3 \\
5 & $-155.4-210.8 i$ & -251 \\
6 & -713 & -3270 \\
7 & -1140 & - \\
8 & -4300 & - \\
9 & -5800 & - \\
$10 / 11$ & $-4300 \pm 4400 i$ & - \\
\hline
\end{tabular}

$G_{\mathrm{ADC}}(f)=S_{\mathrm{d}, \mathrm{ADC}}$.

The sensitivity of this stage is $S_{\mathrm{d}, \mathrm{ADC}}=3.62 \times 10^{5}$ counts $\mathrm{V}^{-1}$, resulting in an overall sensitivity for the LOBSTER seismometers of roughly $7.4 \times 10^{5}$ counts $\left(\mathrm{m} \mathrm{s}^{-1}\right)^{-1}$ at reference frequency $f_{\mathrm{r}}=1 \mathrm{~Hz}$ (see Fig. 4). 
The decimation of the digital signal to the recording frequency is described by a series of $N_{\text {FIR }}$ FIR decimation filters. The $k$ th digital filter stage has $L_{k}$ coefficients $b_{l, k}$, decimating an input signal of sampling rate $\Delta t_{i}$. The total FIR response is the product of the individual FIR stages:

$G_{\mathrm{FIR}}(f)=\prod_{k=1}^{N_{\mathrm{FIR}}} S_{\mathrm{d}, \mathrm{FIR}, k} \sum_{l}^{L_{k}} b_{l, k} e^{2 \pi i \Delta t_{k}}$.

For the DEPAS instruments, the decimation from $512 \mathrm{kHz}$ to 50 or $100 \mathrm{~Hz}$ is described by $8(100 \mathrm{~Hz})$ or $9(50 \mathrm{~Hz})$ FIR stages of uniform sensitivity $S_{\mathrm{d}, \mathrm{FIR}, k}=1$, such that the sensitivity is only affected by the instrument and ADC stages. The coefficients $b_{l, k}$ have been defined by DEPAS and are included in the StationXML and dataless files. They create the sharp cut-off at $90 \%$ of the Nyquist frequency in Figs. 4 and 5 .

The INSU Trillium-240OBS seismometers features $M=12$ poles $p_{m}$ and $N=5$ zeros $r_{n}$ in its analogue stage (see Tables A1d and e). The $p_{m}$ and $r_{n}$ were taken from the Trillium-240 user guide, which applies to the 240OBS as well. The sensitivity is $S_{\mathrm{d}, \text { inst }}=598.45 \mathrm{~V}\left(\mathrm{~ms}^{-1}\right)^{-1}$. This is half the value specified in the user guide, since the OBS were connected single-ended. The analogue gain is 0.225 for the horizontal channels and 1.0 for the vertical channel, to maximize the vertical sensitivity while avoiding clipping on the horizontal channel. The sensitivity of the CS5321-2 A/D converter is 1165080 counts $\mathrm{V}^{-1}$, resulting in an overall sensitivity of $6.97 \times 10^{7}$ counts $\left(\mathrm{m} \mathrm{s}^{-1}\right)^{-1}$ on the horizontal and $1.57 \times 10^{8}$ counts $/\left(\mathrm{m} \mathrm{s}^{-1}\right)^{-1}$ on the vertical channels, both at reference frequency $f_{\mathrm{r}}=1 \mathrm{~Hz}$. The decimation from 8000 to $62.5 \mathrm{~Hz}$ is implemented by 7 FIR stages of uniform sensitivity.

\section{A2 DEPAS hydrophones}

The responses of the hydrophones and differential pressure gauges are also given by Eq. (A2), though with a different instrument response $G_{\text {inst, }}(f)$, that has to be calculated separately for each instrument, as briefly explained here: a hydrophone measures pressure variations via a piezo element, which has a sensitivity of $S_{\mathrm{d} \text {,hyd }}$ in $\mathrm{V} \mathrm{Pa}^{-1}$. Below its corner frequency (typically in the $\mathrm{kHz}$ range), its equivalent circuit is a capacitor $C_{\text {hyd }}$. Together with the input capacity of the amplifier $C_{\mathrm{amp}}$, the system has the total capacitance $C_{\text {total }}=\frac{C_{\text {amp }} C_{\text {hyd }}}{C_{\text {amp }}+C_{\text {hyd }}}$. With the input impedance $R$ of the sensor, the system forms a high-pass filter with a transfer function

$G_{\text {inst, } \mathrm{h}}(f)=S_{\mathrm{d}, \mathrm{hyd}} \frac{R C_{\text {total } 2} 2 \pi i f}{1+R C_{\text {total }} 2 \pi i f}$,

equivalent to Eq. (A1) with a single pole
$p_{1}=-\frac{1}{R C_{\mathrm{total}}}=-\frac{C_{\mathrm{amp}}+C_{\mathrm{hyd}}}{R C_{\mathrm{amp}} C_{\mathrm{hyd}}} \mathrm{rad} \mathrm{s}^{-1}$

and one zero $r_{1}=0 \mathrm{rad} \mathrm{s}^{-1}$.

The capacitance $C_{\text {hyd }}$ is instrument-specific. The reference value from the manufacturer HighTechInc is $C_{\text {hyd }}=45 \mathrm{nF}$. Before sale, every hydrophone is calibrated, which showed a mean value $C_{\text {hyd }}=56.3 \mathrm{nF}$ with a sample standard deviation of $3.5 \mathrm{nF}$ amongst the 60 instruments in the DEPAS pool. The input resistance $R$ of the data logger was either 210 or $500 \mathrm{M} \Omega$, depending on the instrument version.

The sensitivity $S_{\mathrm{h}}$ is different for each hydrophone, around $185 \mu \mathrm{V} \mathrm{Pa}^{-1}$ with a sample standard deviation of $8 \mu \mathrm{V} \mathrm{Pa}^{-1}$ amongst the DEPAS instruments. DEPAS supplied us with values for $S_{\mathrm{d}}, R$ and $C_{\mathrm{hyd}}$ for each instrument. From those, we calculated poles, zeros and sensitivities, which are listed in the dataless SEED and StationXML files available from the RESIF data centre. Geomar instruments were equipped with a similar hydrophone model, HTI01-PCA from the same manufacturer. Its nominal values is $C_{\text {hyd }}=50 \mathrm{nF}$ and since no individually calibrated responses were available, we used the average value of the other HTI01-PCA in the DEPAS pool, resulting in $S_{\mathrm{d}}=199.5 \mu \mathrm{V} \mathrm{Pa}^{-1}$ and $p_{1}=0.10774 \mathrm{rad} \mathrm{s}^{-1}$. This applies to the Geomar OBS (RR33, RR39, RR53 and RR56) as well as to RR45 and RR55, where Geomar hydrophones were attached to LOBSTER OBS.

\section{A3 INSU differential pressure gauges}

Differential pressure gauges (DPGs, Cox et al., 1984) are hand-manufactured in research laboratories and their sensitivity and low-pass frequency are challenging to calibrate. The DPGs in stations RR28 and RR29 were manually calibrated on land by comparing their impulse response to that of an absolute pressure gauge in a vacuum jar. Since the lowpass frequency is highly dependent on the viscosity of the oil in the gauge and this viscosity may change with temperature and pressure, it is not sure that these values accurately reflect the instrument response at the seafloor, although visual comparison with the DEPAS hydrophone PPSDs does not suggest significant error. The DPGs on the other sensors were not calibrated and the instrument responses given are therefore the same as those for station RR28. This practice is the same as that used by other OBS facilities (e.g. Godin et al., 2013), but it leaves a significant uncertainty in the converted signal amplitudes.

\section{Appendix B: Description of laboratory experiments on the DEPAS clocks}

Since the internal clocks of several DEPAS OBS stopped before retrieval, and ambient noise estimation of the clock error proved impossible, we tried to estimate the clock error 
from laboratory experiments. Hence we re-ran several data recorders after their return to the DEPAS lab at AWI Bremerhaven, in an attempt to measure their clock drifts. Only seven data loggers were available (RR06, RR11, RR41, RR43, RR44, RR45, RR55); the remainder had been redeployed in new experiments. Attached to their original lithium batteries and a seismometer, the recorders were run for 7 days, and then for another 33 days. Table B1 shows the skews measured after the two runs, linearly extrapolated to a hypothetical run time of 365 days.

For 6 out of 7 stations, skew values from the two runs agree to within less than $0.1 \mathrm{~s}$. The exception is RR44, where the skews disagree by more than one second $(-0.50 \mathrm{~s}$ from the 7-day run, versus +0.55 s from the 33 -day run). For RR11, a skew of $+0.61 \mathrm{~s}$ had been obtained upon OBS recovery (see Table 3), as compared to -0.15 and $-0.21 \mathrm{~s}$ in the two lab runs (Table B1), which means mutual consistence to within $0.8 \mathrm{~s}$, an uncertainty as large as the skew estimates themselves. No skew upon recovery was available for the remaining six recorders.

Most lab skew values in Table B1 are rather small in magnitude, compared to skews obtained during the field campaign in Table 3 . This pattern is consistent with the direct comparison available for RR11, and hints at a systematic difference between seafloor runs and lab runs. In either setting, the clocks tend to run too fast, as indicated by mostly positive skew values (upon recovery, the elapsed recorder time is larger than the elapsed GPS time). But clocks on the seafloor ran even faster than clocks in the lab. (Note that only DEPAS stations in Table 3 should enter this comparison, since INSU recorders are of a different make.)

The likely shortcoming of our lab experiments is that we did not simulate temperature conditions of the real experiment: a sudden drop from 22 to $4^{\circ} \mathrm{C}$ ) upon deployment, a constant $4{ }^{\circ} \mathrm{C}$ during recording, and sudden warming to $22^{\circ} \mathrm{C}$ upon recovery. Solid-state oscillators are known to be temperature dependent, which may explain why our lab experiments could match the field observations qualitatively (correct sign of skew), but probably did not yield the correct skew magnitudes. Hence we assign low confidence to the skew measurements in Table B1 and do not apply any skew corrections to RHUM-RUM time series based on these values.
Table B1. Lab measurements of clock skews for seven DEPAS recorders. Two separate runs of 7 and 33 days durations yielded skew measurements that are linearly extrapolated to a hypothetical run of 365 days duration (for convenient comparison to skews measured in the field campaign, Table 3). We assign low confidence to these lab measurements (see text for discussion) and do not correct RHUM-RUM time series using these values.

\begin{tabular}{lcrr}
\hline Station & Serial number & \multicolumn{2}{c}{ Skew prediction for 365 days } \\
\cline { 3 - 4 } & (data logger) & from 7 day exp. & from 33 day exp. \\
\hline RR06 & 060744 & $0.15 \mathrm{~s}$ & $0.13 \mathrm{~s}$ \\
RR11 & 060753 & $-0.15 \mathrm{~s}$ & $-0.21 \mathrm{~s}$ \\
RR41 & 050922 & $0.3 \mathrm{~s}$ & $0.23 \mathrm{~s}$ \\
RR43 & 060702 & $0.00 \mathrm{~s}$ & $0.033 \mathrm{~s}$ \\
RR44 & 060751 & $-0.5 \mathrm{~s}$ & $0.55 \mathrm{~s}$ \\
RR45 & 080104 & $0.045 \mathrm{~s}$ & $-0.05 \mathrm{~s}$ \\
RR55 & 060748 & $0.0015 \mathrm{~s}$ & $-0.03 \mathrm{~s}$ \\
\hline
\end{tabular}

\section{Appendix C: Summary charts of noise levels across the RHUM-RUM OBS network}

Figures C1 to C3 are graphical summaries of noise statistics for all stations and components, in three different frequency bands:

Fig. C1: microseismic noise band (period range 5-15s). DEPAS and INSU seismometers record comparable noise levels.

Fig. C2: low-noise notch (period band 15-40 s). The noise level of the INSU seismometers is on average $15 \mathrm{~dB}$ lower than the values for the DEPAS instruments.

Fig. C3: long-period band (40-100 s). Both INSU seismometers (corner period $240 \mathrm{~s}$ ) and the DEPAS seismometers (corner period $60 \mathrm{~s}$ ) still have nominal instrument sensitivity in this band, but the self-noise of the Güralp instruments used in the DEPAS OBS is pronounced, especially on the BHZ channel.

Probabilistic Power Spectral Densities (cf. Fig. 9) were calculated for all stations and broadband components (BH1, BH2, BHZ, BDH) by stacking hour-long time series. For each of the three frequency bands, we averaged the hourly spectra over the frequencies contained the band of interest, and calculated the median, quartiles, $2.5 \%$ percentile, and $97.5 \%$ percentile power levels of the hourly band averages. These statistics are plotted for all stations, components and frequency bands in Figs. C1 to C3. 

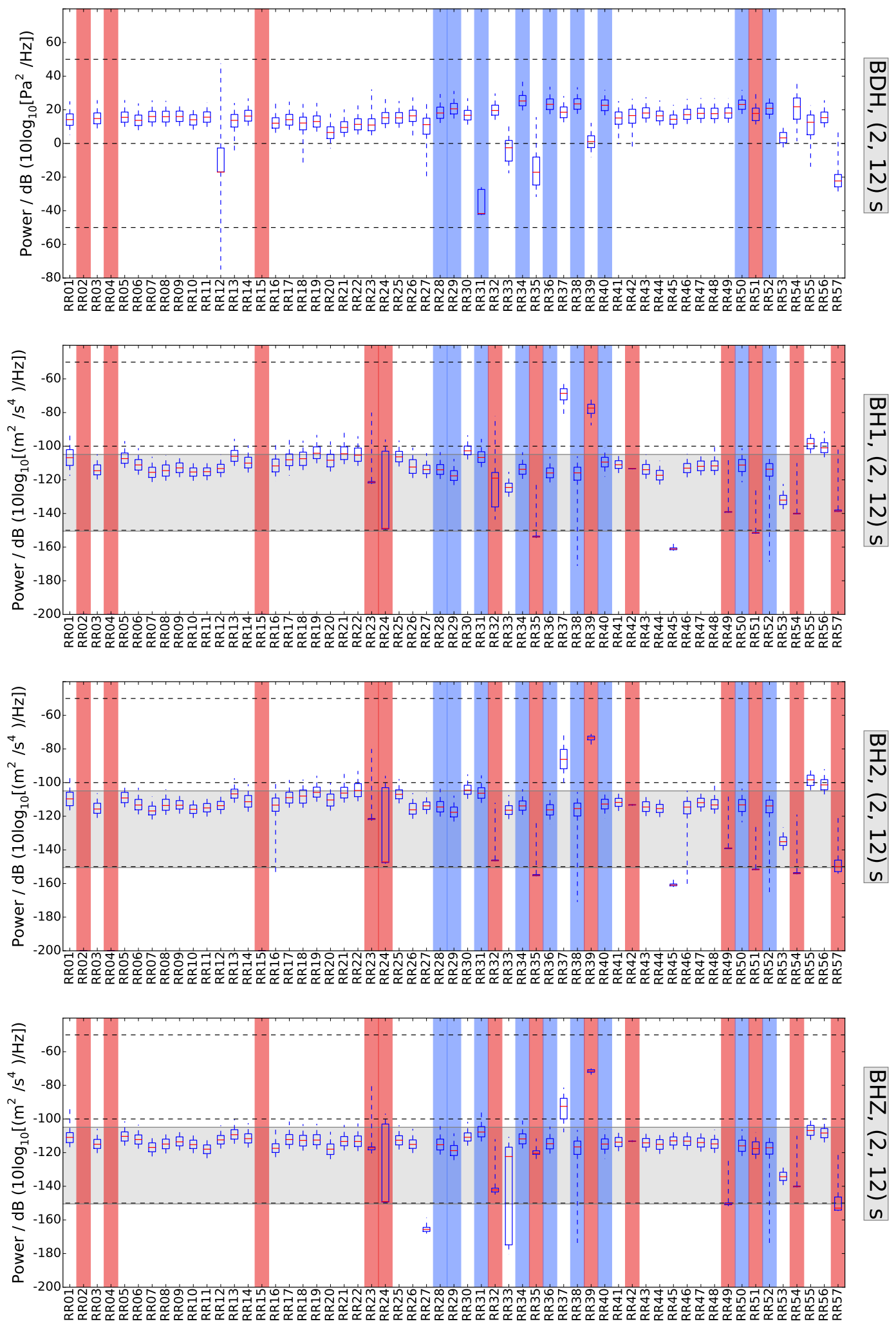

Figure C1. Noise power levels in the microseismic noise band (5-15 s period), on the BH1, BH2, BHZ, and BDH components (4 sub-plots). 57 box plots per panel characterize the 57 RHUM-RUM stations. In each box plot, the red line marks the median power level during the interval of successful recording. Top and bottom edges of the blue box mark the ranges of the two quartiles, and dashed line the range that contains $95 \%$ of all hourly observations in this frequency band (from 2.5 to $97.5 \%$ percentile). Light blue shading indicates INSU stations, all others are DEPAS or Geomar. Red shading indicates failed components. Grey horizontal band marks the power range bracketed by the (terrestrial) New Low Noise and New High Noise Models (Peterson, 1993), in the frequency passband considered here. 

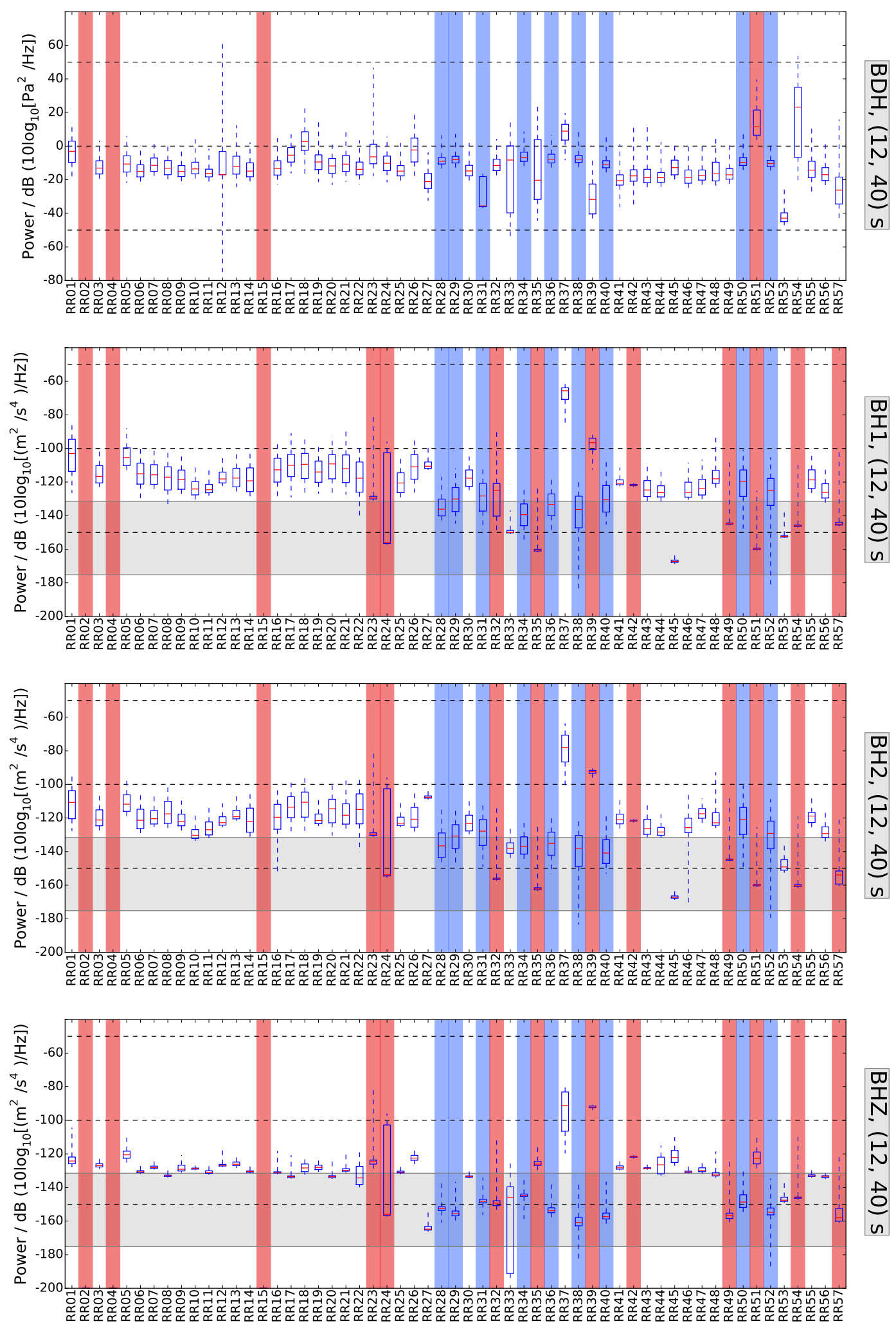

Figure C2. Noise power levels in the band of the low-noise notch (15-40 s period). Refer to the caption of Fig. C1 for explanation. 

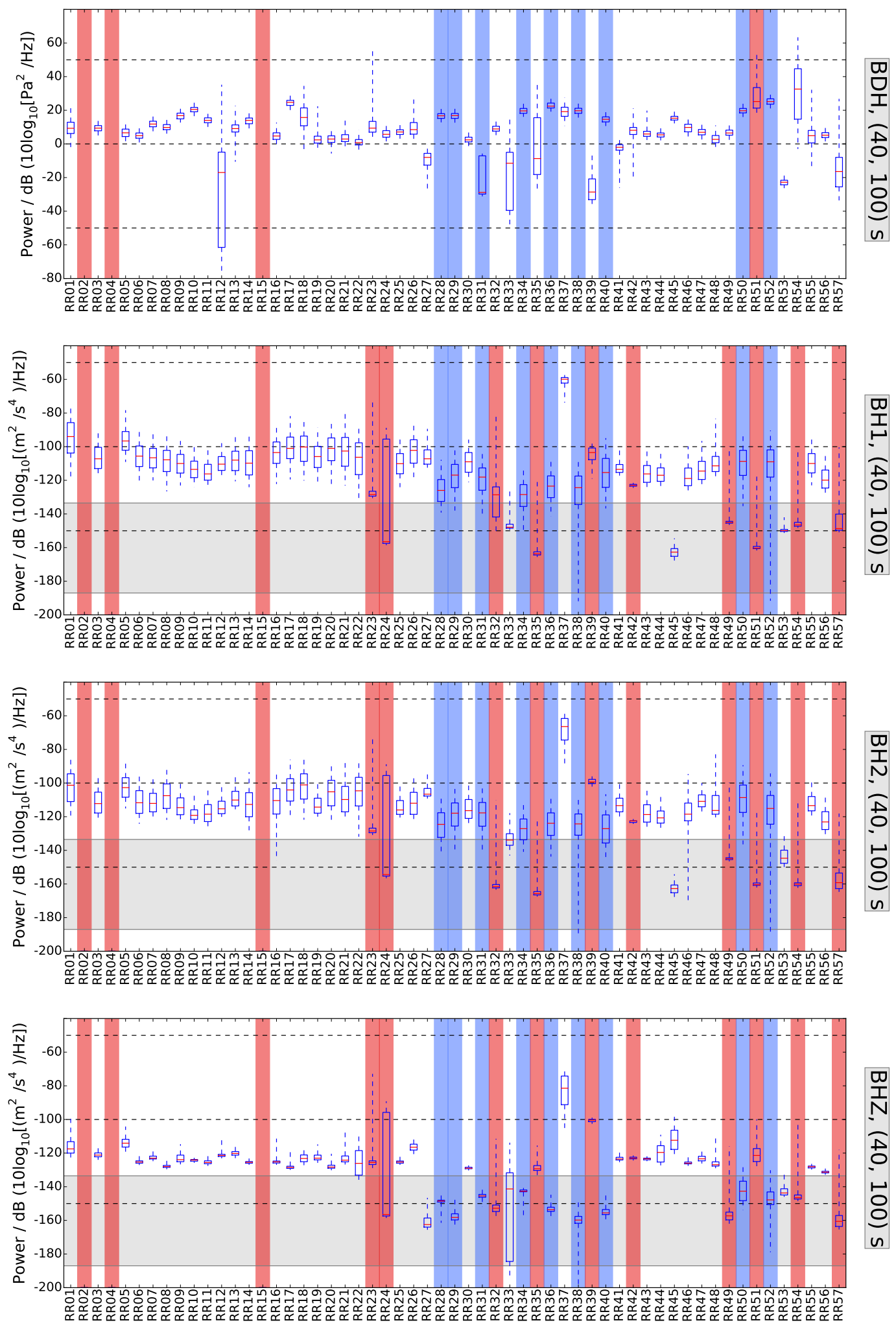

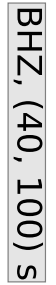

Figure C3. Noise power levels in the long-period band (40-100 s period). Refer to the caption of Fig. C1 for explanation. 


\section{The Supplement related to this article is available online at doi:10.5194/adgeo-4-43-2016-supplement.}

Author contributions. K. Hosseini, M. Tsekhmistrenko, K. Sigloch, S. C. Stähler, W. C. Crawford, J.-R. Scholz and A. Mazzullo processed raw data and assessed station performance during and after the OBS recovery cruise. Station meta-data were assembled and verified for the DEPAS instruments by S. C. Stähler and M. C. Schmidt-Aursch, and for the INSU instruments by W. C. Crawford. A. Mazzullo, M. Deen and W. C. Crawford investigated the "glitch" on the INSU instruments. G. Barruol and K. Sigloch designed the RHUM-RUM project, obtained funding for the OBS experiment, and led the cruises. S. C. Stähler and K. Sigloch prepared the manuscript with contributions from all co-authors.

Acknowledgements. RHUM-RUM is funded by Deutsche Forschungsgemeinschaft (grants SI1538/2-1 and SI1538/4-1) and Agence National de la Recherche (project ANR-11-BS56-0013). Additional support is provided by Centre National de la Recherche Scientifique-Institut National des Sciences de l'Univers, Terres Australes et Antarctiques Françaises, Institut Polaire Paul Emile Victor, Alfred Wegener Institute Bremerhaven, and a Marie Curie Career Integration Grant to K. Sigloch. Instruments were provided by "Deutscher Geräte-Pool für Amphibische Seismologie" at Alfred-Wegener-Institut, Bremerhaven, "Parc Sismomètre fond du mer" at INSU/IPGP, and Geomar, Kiel. We thank Erik Labahn, Henning Kirk, and the crews of research vessels Marion Dufresne and Meteor for excellent support during deployment and recovery. We thank Carlos Corela for preparing the initial compilation of the DEPAS metadata. Ulf Gräwe assisted with downloading HYCOM ocean model data (http://hycom.org). All figures were produced with the ObsPy software, version 0.10.2 (The ObsPy Development Team, 2015). We thank the RESIF data centre in Grenoble, especially Catherine Pequegnat and Pierre Volcke, for hosting the RHUM-RUM data.

RESIF is supported by the French Ministry of Education and Research, by 18 Research Institutions and Universities in France, by the French National Research Agency (ANR) as part of the "Investissements d'Avenir" program (reference: ANR-11EQPX-0040) and by the French Ministry of Ecology, Sustainable Development and Energy.

Edited by: D. Pesaresi

Reviewed by: D. Suetsugu and three anonymous referees

\section{References}

Ahern, T. K., Casey, R., Barnes, D., Benson, R., and Knight, T.: Seed Reference Manual, Tech. rep., Incorporated Research Institutions for Seismology, http://www.fdsn.org/media/ _s/publications/SEEDManual_V2.4.pdf (last access: 19 October 2015), 2012.

Barruol, G.: PLUME investigates South Pacific Superswell, Eos, Trans. Am. Geophys. Union, 83, 511, doi:10.1029/2002EO000354, 2002.

Barruol, G. and Sigloch, K.: Investigating La Réunion hot spot from crust to core, Eos, Trans. Am. Geophys. Union, 94, 205-207, doi:10.1002/2013EO230002, 2013.

Barruol, G., Sigloch, K., and the RHUM-RUM group: RHUMRUM experiment, 2011-2015, code YV (Réunion Hotspot and Upper Mantle - Réunion's Unterer Mantel) funded by ANR, DFG, CNRS-INSU, IPEV, TAAF, instrumented by DEPAS, INSU-OBS, AWI and the Universities of Muenster, Bonn, La Réunion, doi:10.15778/RESIF.YV2011, 2011.

Becker, J. J., Sandwell, D. T., Smith, W. H. F., Braud, J., Binder, B., Depner, J., Fabre, D., Factor, J., Ingalls, S., Kim, S.-H., Ladner, R., Marks, K., Nelson, S., Pharaoh, A., Trimmer, R., Von Rosenberg, J., Wallace, G., and Weatherall, P.: Global Bathymetry and Elevation Data at 30 Arc Seconds Resolution: SRTM30_PLUS, Mar. Geodyn., 32, 355-371, doi:10.1080/01490410903297766, 2009.

Cannat, M., Rommevaux-Jestin, C., Sauter, D., Deplus, C., and Mendel, V.: Formation of the axial relief at the very slow spreading Southwest Indian Ridge ( $49^{\circ}$ to $69^{\circ} \mathrm{E}$ ), J. Geophys. Res. 104, 22825, doi:10.1029/1999JB900195, 1999.

Cox, C., Deaton, T., and Webb, S.: A Deep-Sea Differential Pressure Gauge, J. Atmos. Ocean. Tech., 1, 237-246, doi:10.1175/1520-0426(1984)001<0237:ADSDPG>2.0.CO;2, 1984.

Crawford, W. C. and Webb, S. C.: Identifying and Removing Tilt Noise from Low-Frequency $(<0.1 \mathrm{~Hz})$ Seafloor Vertical Seismic Data, Bull. Seismol. Soc. Am., 90, 952-963, doi:10.1785/0119990121, 2000.

Cummings, J. A.: Operational multivariate ocean data assimilation, Q. J. Roy. Meteorol. Soc., 131, 3583-3604, doi:10.1256/qj.05.105, 2005.

Dahm, T., Thorwart, M., Flueh, E. R., Braun, T., Herber, R., Favali, P., Beranzoli, L., D’Anna, G., Frugoni, F., and Smriglio, G.: Ocean bottom seismometers deployed in Tyrrhenian Sea, Eos, Trans. Am. Geophys. Union, 83, 309, doi:10.1029/2002EO000221, 2002.

Davy, C., Barruol, G., Fontaine, F. R., Sigloch, K., and Stutzmann, E.: Tracking major storms from microseismic and hydroacoustic observations on the seafloor, Geophys. Res. Lett., 41, 88258831, doi:10.1002/2014GL062319, 2014.

Duennebier, F. K., Blackinton, G., and Sutton, G. H.: Currentgenerated noise recorded on ocean bottom seismometers, Mar Geophys. Res., 5, 109-115, doi:10.1007/BF00310316, 1981.

Dyment, J., Lin, J., and Baker, E.: Ridge-Hotspot Interactions: What Mid-Ocean Ridges Tell Us About Deep Earth Processes, Oceanography, 20, 102-115, doi:10.5670/oceanog.2007.84, 2007.

Flueh, E. R. and Biolas, J.: A digital, high data capacity ocean bottom recorder for seismic investigations, Int. Underw. Syst. Des., 18, 18-20, 1996. 
Geissler, W. H. and Schmidt, R.: Short Cruise Report Maria S. Merian; MSM 24 Walvis Bay - Cape Town, Tech. rep., Leitstelle Deutsche Forschungsschiffe, Hamburg, https://www.ldf.uni-hamburg.de/merian/wochenberichte/ wochenberichte-merian/msm22-msm25/msm24-scr.pdf (last access: 19 October 2015), 2013.

Geissler, W. H., Matias, L., Stich, D., Carrilho, F., Jokat, W., Monna, S., Ibenbrahim, A., Mancilla, F., Gutscher, M. A., Sallars, V., and Zitellini, N.: Focal mechanisms for sub-crustal earthquakes in the Gulf of Cadiz from a dense OBS deployment, Geophys. Res. Lett., 37, 7-12, doi:10.1029/2010GL044289, 2010.

GEOFON: Mw 6.6 earthquake, Sichuan China, 2013-04-20 (Moment Tensor Solution), doi:10.5880/GEOFON.gfz2013hrdy, 2013.

Godin, O. A., Zabotin, N. A., Sheehan, A. F., Yang, Z., and Collins, J. A.: Power spectra of infragravity waves in a deep ocean, Geophys. Res. Lett., 40, 2159-2165, doi:10.1002/grl.50418, 2013.

Gouedard, P., Seher, T., McGuire, J. J., Collins, J. A., and van der Hilst, R.: Correction of Ocean-Bottom Seismometer Instrumental Clock Errors Using Ambient Seismic Noise, Bull. Seismol. Soc. Am., 104, doi:10.1785/0120130157, 2014.

Hannemann, K., Krüger, F., and Dahm, T.: Measuring of clock drift rates and static time offsets of ocean bottom stations by means of ambient noise, Geophys. J. Int., 196, 1034-1042, doi:10.1093/gji/ggt434, 2014.

Laske, G., Collins, J. A., Wolfe, C. J., Solomon, S. C., Detrick, R. S., Orcutt, J. A., Bercovici, D., and Hauri, E. H.: Probing the Hawaiian Hot Spot With New Broadband Ocean Bottom Instruments, Eos, Trans. Am. Geophys. Union, 90, 362-363, doi:10.1029/2009EO410002, 2009.

McNamara, D. E. and Buland, R.: Ambient Noise Levels in the Continental United States, Bull. Seismol. Soc. Am., 94, 15171527, doi:10.1785/012003001, 2004.

Meier, T., Friederich, W., Papazachos, C., Taymaz, T., and Kind, R.: EGELADOS: a temporary amphibian broadband seismic network in the southern Aegean, in: Geophys. Res. Abstr., 9, 9020, 2007.

Morgan, W. J.: Rodriguez, Darwin, Amsterdam, ..., A second type of Hotspot Island, J. Geophys. Res., 83, 5355, doi:10.1029/JB083iB11p05355, 1978.

Peterson, J.: Observations and Modeling of Seismic Background Noise, Tech. rep., USGS, Albuquerque, New Mexico, 1993.

Ponsoni, L., Aguiar-González, B., Maas, L., van Aken, H., and Ridderinkhof, H.: Long-term observations of the east madagascar undercurrent, Deep-Sea Res. Pt. I, 100, 64-78, doi:10.1016/j.dsr.2015.02.004, 2015.
Scholz, J.-R.: Local seismicity of the segment-8-volcano at the ultraslow spreading Southwest Indian Ridge, Diploma thesis, Technische Universität Dresden, Dresden, 2014.

Sens-Schönfelder, C.: Synchronizing seismic networks with ambient noise, Geophys. J. Int., 174, 966-970, doi:10.1111/j.1365246X.2008.03842.x, 2008.

Sigloch, K.: Multiple-frequency body-wave tomography, $\mathrm{PhD}$ thesis, Princeton, 2008.

Stähler, S. C., Sigloch, K., Barruol, G., and Crawford, W. C.: Noise levels at all stations of the RHUM-RUM OBS network, doi:10.13140/RG.2.1.1374.0886, 2015.

Suetsugu, D., Sugioka, H., Isse, T., Fukao, Y., Shiobara, H., Kanazawa, T., Barruol, G., Schindelé, F., Reymond, D., Bonneville, A., and Debayle, E.: Probing South Pacific mantle plumes with ocean bottom seismographs, Eos, Trans. Am. Geophys. Union, 86, 429, doi:10.1029/2005EO440001, 2005.

Suetsugu, D., Shiobara, H., Sugioka, H., Ito, A., Isse, T., Kasaya, T., Tada, N., Baba, K., Abe, N., Hamano, Y., Tarits, P., Barriot, J.-P., and Reymond, D.: TIARES Project - Tomographic investigation by seafloor array experiment for the Society hotspot, Earth Planets Space, 64, i-iv, doi:10.5047/eps.2011.11.002, 2012.

Sumy, D. F., Lodewyk, J. A., Woodward, R. L., and Evers, B.: Ocean-Bottom Seismograph Performance during the Cascadia Initiative, Seismol. Res. Lett., 86, 1238-1246, doi:10.1785/0220150110, 2015.

The ObsPy Development Team: ObsPy 0.10.2, doi:10.5281/zenodo.17641, 2015.

Tilmann, F., Yuan, X., Rümpker, G., and Rindraharisaona, E.: SELASOMA Project, Madagascar 2012-2014, doi:10.14470/MR7567431421, 2012.

Trehu, A. M.: A note on the effect of bottom currents on an ocean bottom seismometer, Bull. Seismol. Soc. Am., 75, 1195-1204, 1985.

Webb, S. C.: Broadband seismology and noise under the ocean, Rev. Geophys., 36, 105, doi:10.1029/97RG02287,1998.

Wolfe, C. J., Solomon, S. C., Laske, G., Collins, J. A., Detrick, R. S., Orcutt, J. A., Bercovici, D., and Hauri, E. H.: Mantle Shear-Wave Velocity Structure Beneath the Hawaiian Hot Spot, Science, 326, 1388-1390, doi:10.1126/science.1180165, 2009.

Wysession, M., Wiens, D., Nyblade, A., and Rambolamanana, G.: Investigating Mantle Structure with Broadband Seismic Arrays in Madagascar and Mozambique, AGU Fall Meet. Abstr., p. B2591, 2012. 